\title{
EL INCUMPLIMIENTO CONTRACTUAL Y LOS REMEDIOS DE QUE DISPONE EL ACREEDOR EN LA COMPRAVENTA INTERNACIONAL*
}

\author{
Álvaro R. Vidal Olivares**
}

\begin{abstract}
RESUMEN: En la Convención de Viena se recoge un concepto amplio y objetivo de incumplimiento y pone a disposición del acreedor una serie de remedios entre los cuales puede optar libremente. Empero, la Convención le impone una gestión razonable de los efectos del incumplimiento que se manifiesta en la necesidad de observar cargas de comunicación y de conducta material. La Convención atribuye al deudor una responsabilidad objetiva y estricta y ella se extiende a todos los daños que sean una consecuencia del incumplimiento razonablemente previsible al momento del contrato, con exclusión de aquellos daños que el acreedor habría podido prevenir o evitar de haber observado una conducta razonable. La exoneración de responsabilidad solo incide directamente en la indemnización de daños, no así respecto de los restantes remedios como son la pretensión de cumplimiento, incluidas sus modalidades de reparación y sustitución de las mercaderías no conformes, la reducción del precio y la resolución del contrato.
\end{abstract}

Palabras clave: Compraventa internacional, incumplimiento, remedios.

ABSTRACT: The Viena Convention adopts a wide and objective concept of noncompliance and offers the creditor a series of remedies to freely choose from. However, the Convention requires him or her to reasonably manage the effects of this noncompliance, meaning that he or she has to respect communication and material conduct requirements. The Convention establishes that the debtor's liability is objective and strict and it extends to all damages following reasonably foreseeable non compliance at the time of the contract, while excluding all those damages that the creditor would have been able to prevent from happening or to to avoid if he or she had adopted a reasonable conduct. The exoneration of liability only influences directly the damages compensation, but it does not affect the other remedies such as the compliance claim (including compensation and mending of all non conform products), the reduction of the price and the termination of the contract.

Key words: International sales, non-compliance, remedies.

\section{IDEAS PRELIMINARES}

La Convención de Viena sobre compraventa internacional de mercaderías, en adelante la Convención ${ }^{1}$, es ley de la República desde el año 1990 (3 de octubre de 1990)²;

\footnotetext{
* El presente trabajo recoge parte de los resultados de la ejecución del Proyecto de Investigación Fondecyt No 1030352, cuyo investigador responsable es el autor.

** Abogado, Doctor en Derecho, Profesor de la Facultad de Derecho de la Pontificia Universidad Católica de Valparaíso, Chile, alvaro.vidal@ucv.cl .

${ }^{1}$ También, en adelante CV o Viena.
} 
sin embargo, no ha habido hasta ahora interés por estudiarla ni tampoco existe sentencia judicial o laudo arbitral conocido emanado de un tribunal nacional que la haya aplicado. Esta situación resulta más crítica si se compara con la de otros Estados partes de la Convención, en los que el interés por conocer, estudiar y aplicar la regulación en ella contenida es creciente; lo que resulta plenamente justificado si se piensa que la Convención regula el instrumento jurídico en que se materializan las operaciones de importación y exportación de mercaderías, propias del comercio internacional, tan importante para las economías nacionales de nuestros días. Este interés, y he aquí lo que justifica este trabajo, también se explica porque la Convención contiene una regulación del contrato y sus efectos que atiende a las actuales condiciones del tráfico y que, por esta razón, ha servido de base para revisar el derecho interno sobre la materia, especialmente en los Estados europeos. La Convención de Viena constituye la base sobre la cual se ha venido construyendo lo que se denomina "nuevo derecho de la contratación", el que se encuentra contenido en normas que tienen fuerza de ley y otras que no tienen tal fuerza.

Efectivamente, en el derecho europeo de las obligaciones se vive con distinta intensidad un proceso de adecuación de las disposiciones de los antiguos códigos civiles sobre obligaciones y contratos a las vigentes condiciones del tráfico. Y esta adecuación tiene como modelo inmediato el derecho de la Convención de Viena de 1980 sobre compraventa internacional de mercaderías y, seguidamente, los Principios de Derecho Europeo de los Contratos (en adelante PECL) ${ }^{3}$ y los Principios de Unidroit sobre contratos comerciales internacionales (en adelante PCCI) ${ }^{4}$. A la cabeza del nuevo derecho de la contratación, como se le denomina, se hallan estos tres ordenamientos, uno con fuerza de ley y los otros dos de aplicación convencional.

A lo anterior se suma la Directiva 1999/44/CE del Parlamento Europeo y del Consejo de 25 de mayo de 1999 sobre determinados aspectos de la venta y las garantías de los bienes de consumo (99/44/CEE) que desplaza para esta clase de compraventas el tradicional sistema de las acciones edilicias por uno más amplio, el de la falta de confor-

\footnotetext{
${ }^{2}$ El Estado de Chile ratifica la Convención, declarando, de conformidad con los artículos 12 y 96 de la misma, que cualquier disposición del art. 11, del art. 29, o de la Parte II de la Convención que permita que la celebración, la modificación o la extinción por mutuo acuerdo del contrato de compraventa, o la oferta, la aceptación o cualquier otra manifestación de intención, se hagan por procedimiento que no sea por escrito no se aplicará en el caso de que cualquiera de las partes tenga su establecimiento en Chile.

${ }^{3}$ LANDO (2000); DíEZ-PICAZO et al. (2002). Estos principios carecen de fuerza vinculante directa, ellos deben incorporarse al contrato por un acuerdo entre las partes o por aplicación de las prácticas establecidas anteriormente por ellas mismas o de los usos del tráfico (elementos de interpretación integradora del contrato). En el art. 1101 de los Principios se lee: "Estos principios deberán aplicarse cuando las partes hayan acordado que su contrato se rija por ellos”. En este trabajo citaré la traducción contenida en la obra de los citados autores españoles.

${ }^{4}$ Aprobados en el mes de mayo de 1994 por el Consejo de Gobierno de UNIDROIT y cuya última versión fue aprobada el año 2005. Los Principios de UNIDROIT, los comentarios a sus artículos y jurisprudencia que los ha aplicado se encuentran en el sitio http://www.unilex.info. Estos principios, al igual que los PECL, carecen de fuerza vinculante directa y deben incorporarse al contrato por un acuerdo entre las partes o por aplicación de las prácticas establecidas anteriormente por ellas mismas o de los usos del tráfico (elementos de interpretación integradora del contrato). En el preámbulo de los Principios se lee: "Estos principios deberán aplicarse cuando las partes hayan acordado que su contrato se rija por ellos".
} 
midad de la $\operatorname{cosa}^{5}$. La ordenación es prácticamente idéntica a la de la Convención de Viena para la falta de conformidad de las mercaderías y sus efectos ${ }^{6}$.

En cuanto a las experiencias en el derecho interno comparado, el año 2002 se modificó sustancialmente el BGB alemán, modificación a la que se denominó la "gran solución"7. En el caso del derecho civil español, sin una reforma legislativa, primero la doctrina de los autores ${ }^{8}$ y después los Tribunales, han adaptado a las actuales condiciones del tráfico las normas de derecho civil sobre obligaciones y contratos del Código Civil, similares y en algunos casos idénticas a las del Código Civil chileno9 ${ }^{9}$. Recientemente en España se publicó una Propuesta de Anteproyecto de ley de modificación del Código Civil en materia de contrato de compraventa, elaborada por miembros de la Comisión General de Codificación que persigue avanzar en el proceso de modernización del derecho de las obligaciones ${ }^{10}$.

La regulación de la Convención de Viena resulta plenamente apropiada para los contratos entre vendedores profesionales y consumidores; y entre particulares. Muestra de ello son es el mismo BGB modificado, la Propuesta de Anteproyecto de Modificación del Código civil español en materia de compraventa; y los PECL, que son de aplicación general a todo contrato cuando así las partes lo han acordado.

Sin embargo, a pesar de lo expresado, se percibe que en Chile la doctrina considera que la Convención es un cuerpo de escasa importancia en el terreno práctico y por ello se le ha dejado de lado, viéndose perjudicada su difusión y aplicación a nivel nacional ${ }^{11}$.

Chile es un país que desde hace tiempo cuenta con una economía abierta y dependiente del comercio internacional y, pese a ello, nuestros exportadores -vendedo-

\footnotetext{
${ }^{5}$ Aunque debe reconocerse que hasta antes de la Directiva, ya en materia de protección del consumidor de bienes los remedios por el incumplimiento contractual del proveedor se alejaban de los tradicionales de la compraventa civil. Así en España la Ley No 26, de 1984, contemplaba los remedios disponibles para el consumidor en caso de producto defectuoso. Véase: FENOY (1996) pp. 347-364.

${ }^{6}$ En Alemania, junto con incorporarse la Directiva, la reforma al BGB, modifica el régimen general de la compraventa acogiendo el régimen de la falta de conformidad para toda compraventa. En todo caso, la reforma no se limita a la compraventa, sino también al derecho general de las obligaciones y del incumplimiento de las mismas, cualquiera sea su fuente. En el derecho español, la Ley No 23, de 2003, incorpora al derecho español la comentada Directiva europea, derogando el art. 11.2 y 3 de la Ley No 26, de 1984. Sobre la Ley No 23, de 2003, y el régimen por falta de conformidad que ella instaura, véase: FENOY (2006).

7 Albiez (2002a) pp. 1133-1227; Albiez (2002b) pp. 187 y ss; INFANTE (2002) pp. 152 y ss; LAMARCA (2001); EBERS (2003) pp. 1575-1608.

${ }^{8}$ Van en esta dirección: DíEz-PiCAZo (1996a) y DíEz-PiCAZo (2005b); Morales (2003a) pp. 109-149; MORales (2004b) pp. 39-60; MORAles (2005c) pp. 261-270; MORALES (2003d) pp. 1609-1651; FenOY (1996a); FenOY (2005b); FenOY (2006c); PANTALEÓn (1991a) pp. 1019-1091; PANTAleón (1993b) 4, pp. 1719-1745; y SAN Miguel (2004).

9 Por ello estimo plenamente justificado el recurso a la doctrina española para interpretar las disposiciones contenidas en nuestro Código Civil.

10 BIMJ., de 2005, pp. 2076-2091.

11 Son pocos los trabajos de la doctrina nacional que hacen objeto de estudio a la Convención de Viena y al derecho que ella instaura. A vía ejemplar puede mencionarse el trabajo del Licenciado en Ciencias Jurídicas de la Pontificia Universidad Católica de Valparaíso, Martín Loo, y que corresponde a su memoria de grado LoO, 2005) dirigida por el suscrito y que fuera premiada por la Fundación Fueyo L. A ello se suma el reciente trabajo que ofrece una visión general sobre el derecho de la Convención de Viena, Paillas (2006).
} 
res internacionales- no son conscientes que por el solo hecho de celebrar el contrato en que se materializa la exportación, quedan sometidos a la Convención, absolutamente desconocida para ellos. Hoy día esta consideración adquiere mayor relieve si se tiene en cuenta la entrada en vigencia de los Tratados de Libre Comercio con la Unión Europea y con los Estados Unidos de Norteamérica. Tanto en los Estados europeos como en los Estados Unidos de Norteamérica la Convención no solo es ley formal, sino que es ley supletoria aplicable a las compraventas internacionales de mercaderías y a los conflictos con ellas relacionados. Precisamente, en estos Estados la Convención ha tenido una mayor acogida y día a día se dictan nuevos fallos que la aplican e interpretan, contribuyendo a su desarrollo uniforme como norma nueva. El desconocimiento en Chile de la Convención coloca en una situación de abierta desventaja a nuestros operadores del tráfico, quienes se comportan bajo el convencimiento que la norma aplicable a sus negocios es la supletoria de la voluntad contenida en los Códigos de Comercio y Civil, en circunstancias que lo es un derecho nuevo, desconocido y ajeno a la cultura jurídica chilena, el contenido en Viena. Y, por consiguiente, si surge un conflicto entre las partes del contrato y este es llevado al conocimiento y resolución de un tribunal -ordinario o arbitral- extranjero, sin duda lo resolverá conforme el derecho de la Convención, excluyendo el derecho interno, incluso cuando exista una cláusula de sometimiento a las leyes chilenas ${ }^{12}$. Ahora, ¿qué sucederá cuando el juez, o árbitro, es chileno?, muy simple: o derechamente aplicará erróneamente el derecho interno a un supuesto que cae dentro del ámbito de la Convención, o aplicará esta última, pero como desconoce el derecho que ella contiene, lo hará mecánicamente, sin considerar los conceptos básicos y principios generales en que se apoya y que orientan su interpretación y aplicación al caso concreto.

Al tratarse de un derecho nuevo, debe estudiarse y aplicarse autónomamente, sin mirar las instituciones y conceptos jurídicos pertenecientes a las tradiciones del derecho interno de los Estados partes. Tanto es así que el sistema de fuentes de la Convención hace un llamado al desarrollo jurisprudencial de sus normas, ordenando que los vacíos, o lagunas, que ella presente se integren, primeramente, por los principios generales de derecho en que ella misma se apoya y si ello no es posible -solo en esa hipótesis- autoriza el recurso a la norma de derecho interno aplicable según el derecho internacional privado $(\text { artículo } 7 \mathrm{CV})^{13}$. El recurso al derecho interno atenta contra la uniformidad que se

\footnotetext{
${ }^{12}$ La Convención de Viena es una ley chilena de aplicación directa cuando concurre el presupuesto en ella previsto $y$, por consiguiente, si las partes incluyen una cláusula genérica de derecho aplicable, en virtud de la cual se someten al derecho chileno o las leyes del Estado de Chile, el juez o árbitro deberá aplicar la Convención que es derecho patrio. La Convención se excluye, como norma aplicable, solo cuando las partes en el contrato, haciendo uso de la libertad de pacto que le reconoce su art. 6, incluyen una cláusula que explícitamente se pronuncie en este sentido.

${ }^{13}$ Artículo 7. "1) En la interpretación de la presente Convención se tendrán en cuenta su carácter internacional y la necesidad de promover la uniformidad en su aplicación y de asegurar la observancia de la buena fe en el comercio internacional. 2) Las cuestiones relativas a las materias que se rigen por la presente Convención que no estén expresamente resueltas en ella se dirimirán de conformidad con los principios generales en los que se basa la presente Convención o, a falta de tales principios, de conformidad con la ley aplicable en virtud de las normas de derecho internacional privado".
} 
pretende alcanzar y ello explica su carácter subsidiario, o de última alternativa, como fuente de integración. No obstante lo anterior, es un hecho que tanto los autores que comentan las disposiciones de la Convención, como los operadores jurídicos que la aplican, llevan sobre sí una fuerte carga ideológico-jurídica a la que están indisolublemente ligados, que les conduce inconscientemente a leer y aplicar sus disposiciones de acuerdo a las ideas legales en que se basa, o apoya, dicha ideología. Esta actitud impide el desarrollo uniforme y autónomo a que aludo y la comprensión del genuino alcance y sentido del régimen jurídico que en el derecho uniforme se instaura. Por ello, y para paliar las consecuencias de este fenómeno, a la fecha no son pocas las iniciativas, tanto de la UNCITRAL, como de otros centros de estudios, destinadas a colaborar para que se cumpla el mandato de aplicación uniforme de la Convención, contenido en el citado artículo 7, destacándose especialmente el trabajo realizado por la Universidad de Pace de los Estados Unidos de Norteamérica, centro que pone a disposición de los operadores jurídicos de todo el mundo una base de datos con toda la información de relevancia sobre el derecho de la compraventa internacional, comprendiendo desde la historia de su establecimiento hasta la jurisprudencia que la ha interpretado y aplicado ${ }^{14}$.

El presente trabajo tiene por objeto el estudio del sistema de remedios por incumplimiento que prevé la Convención de Viena. Para ello seguiré el siguiente itinerario. En la primera sección estudiaré las condiciones de aplicación de la Convención de Viena y su ámbito material; y en una segunda sección de una mayor extensión trataré el incumplimiento contractual, los principios en que se apoya el sistema de remedios, con énfasis en la responsabilidad civil y en la relación de este con los otros remedios, sobre todo cuando habiendo incumplimiento el deudor se exonera de responsabilidad. Concluiré con un cuerpo de conclusiones.

\section{SECCIÓN I. APLICACIÓN DE LA CONVENCIÓN DE VIENA SOBRE COMPRAVENTA INTERNACIONAL DE MERCADERÍAS Y SU ÁMBITO MATERIAL}

\section{A) CONDICIONES DE APLICABILIDAD DE LA CONVENCIÓN DE VIENA}

Desde que la Convención de Viena es ley de la República, todos los contratos de compraventa celebrados en Chile y en los que concurran las condiciones que determinan

\footnotetext{
${ }^{14}$ Existen tres sitios web que mantienen una completa y actualizada información sobre la historia del establecimiento de la Convención, los comentarios que de ellas se hacen por juristas de distintos Estados y, lo más importante, las sentencias y laudos arbitrales que se dictan en los Estados partes de la Convención. Los sitios son: http://www.unilex.info que contiene una colección internacional de casos jurisprudenciales y bibliografía de la Convención de Viena y de los Principios de Unidroit; http://cisgw3.law.pace.edu de la Universidad de Pace denominado "Electronic Library on International Trade Law and the CISG; y http:// www.uncitral.org/uncitral/en/case_law/abstracts.html de UNITRAL. Cabe advertir que UNCITRAL ha elaborado un texto que mantiene actualizado que da cuenta de la aplicación jurisprudencial de la Convención de Viena y que se titula: UNCITRAL Digest of Case Law on the United Nations Convention on the International Sales of Goods, disponible en: http://www.uncitral.org/uncitral/en/case_law/digests.html; texto que es complementado por Pace University y que se encuentra en: http://cisgw3.law.pace.edu/cisg/ text/digest-cases-toc.html.
} 
su aplicación, quedan sometidos a ella con prescindencia de lo que el derecho nacional prescriba sobre la materia. En el caso del derecho chileno, queda excluida la aplicación de las normas de los Códigos de Comercio y Civil. No obstante lo anterior, las partes haciendo uso de su autonomía privada, podrían, o modificar las disposiciones de la Convención, o derogarlas, sometiendo su compraventa a la cláusulas que ellas mismas se den o al derecho interno de cualquier Estado, o a los PCCI, o incluso a los PECL ${ }^{15}$.

\section{Concepto de compraventa internacional de mercaderías}

Decidir si un contrato queda, o no, sometido a la normativa de Viena, implica necesariamente saber qué debe entenderse por compraventa internacional de mercaderías. La Convención no la define, sin embargo, puede construirse un concepto de ella a partir de su propio texto, en particular, de las disposiciones que fijan las obligaciones del vendedor y del comprador ${ }^{16}$. Se desprende de sus artículos 30, 35, 42, 53 y 60 que la compraventa internacional de mercaderías es aquel negocio jurídico sinalagmático celebrado entre un vendedor y un comprador que tienen sus establecimientos en Estados diferentes, pero relacionados con la Convención ${ }^{17}$ y en cuya virtud el primero se obliga a entregar mercaderías conformes al contrato, libres de cualquiera pretensión o derecho de tercero, transmitir su propiedad y entregar cualesquiera otros documentos relacionados con ellas ${ }^{18}$, y el segundo a pagar el precio del contrato, hacer todo lo que razonablemente pueda esperarse de él para que el vendedor realice la entrega; y, finalmente, recibir las mercaderías ${ }^{19}$.

\footnotetext{
15 Estos dos últimos cuerpos normativos son de origen privado y de aplicación convencional, quiere decir que solo adquieren fuerza vinculante en la medida que las partes se someten a ellos, sea expresamente (art. $6 \mathrm{CV}$ ), sea tácitamente por aplicación de las prácticas establecidas entre las partes o los usos del tráfico, que en la Convención de Viena constituyen elementos de interpretación integradora de la declaración de voluntad (art. $9 \mathrm{CV})$.

16 Cfr. VÁSQUEZ (2000) p. 55. Según el autor, la compraventa es el intercambio de la propiedad de una cosa por un precio. En el mismo sentido: BURGHARD (1998) p. 26. El autor afirma que la compraventa internacional es aquel contrato dirigido a conseguir la entrega de mercaderías y la transmisión de su propiedad a cambio de un precio.

17 Para la exacta delimitación del ámbito de aplicación de la Convención no basta observar lo dispuesto por sus artículos 1 y 3, sino, además, es necesario considerar su art. 2 que delimita definitivamente el ámbito de aplicación dibujado a partir de las dos primeras disposiciones. El citado artículo excluye algunas compraventas que tienen el carácter de internacionales. Dos son las categorías de compraventas excluidas. La primera es una genuina compraventa internacional de mercaderías; la segunda, si bien es una compraventa internacional, su objeto no lo constituyen mercaderías. En efecto, el art. 2 establece seis exclusiones que nos permiten, por vía de descarte, delimitar el ámbito de aplicación de Viena, en el sentido que fuera de ellas, toda compraventa internacional de mercaderías se regirá por la Convención.

18 Véanse los artículos 30 y 35 de la CV. Conforme al primero, el vendedor deberá entregar las mercaderías, transmitir su propiedad y entregar cualesquiera documentos relacionados con ellas; y el segundo, en su párrafo (1) el vendedor deberá entregar las mercaderías cuya cantidad, calidad y tipo corresponda a lo estipulado y que estén envasadas y embaladas en la forma fijada por el contrato. Posteriormente, en su párrafo (2) define cuándo las mercaderías no son conforme al contrato.

${ }^{19} \mathrm{El}$ art. 53 de la CV dispone que el comprador deberá pagar el precio de las mercaderías y recibirlas en las condiciones establecidas en el contrato y en la Convención. Por su parte el art. 60 prescribe que la obligación del comprador de proceder a la recepción de las mercaderías consiste en realizar todos los actos que razonablemente quepa esperar de él para que el vendedor pueda efectuar la entrega y en hacerse cargo de las mercaderías.
} 
El concepto propuesto coincide con la compraventa en sentido estricto o tradicional, que se identifica con una simple operación de intermediación o con el intercambio de ciertas mercaderías por un precio. Sin embargo, el artículo $3^{\circ}$ de la Convención, la hace aplicable a otros negocios jurídicos de objeto más complejo, siempre y cuando la parte principal de dicho objeto sean las mercaderías. Puede hablarse de compraventas por asimilación. Si la parte principal está representada por una prestación de hacer, el negocio ni será considerado compraventa ni quedará sometido a la Convención. Como apunta Ferrari se trata de contratos que "no son tipicamente compraventa, es decir, contratos que no son tipicamente de dare, sino que tienen también por objeto un facere" 20 . El citado artículo 3 prevé dos supuestos: el de los contratos de suministro de mercaderías a ser fabricadas o manufacturadas; y el de aquellos en que el vendedor se obliga no solo a la entrega de las mercaderías sino, además, a la prestación de un servicio o mano de obra ${ }^{21}$.

Entonces, al lado de la compraventa tradicional se ubican estos negocios que si bien técnicamente no son compraventa, son usuales en el tráfico comercial internacional.

El carácter de internacional de la compraventa está determinado por una doble condición. Primero, que las partes tengan su establecimiento (place of bussines) 22 en Estados diversos y, segundo, que dichos Estados se relacionen, al menos indirectamente, con la Convención. La internacionalidad de una compraventa se conecta exclusivamente con el criterio del establecimiento que tengan las partes al momento del contrato, siendo irrelevante el lugar de su celebración, como también aquel en el que estén situadas las mercaderías o el lugar al que estas deban ser trasladadas o transportadas para su entre$\mathrm{ga}^{23}$. Por consiguiente, igualmente se regirá por la Convención una compraventa, cuyo objeto son mercaderías situadas y entregadas dentro de un mismo Estado, si una de las partes concernidas tiene su establecimiento en un Estado diverso y este se relacione con la Convención.

Pero, como he expresado, no basta para la aplicación de la Convención con que las partes tengan sus establecimientos en Estados diversos, sino que se requiere, adicionalmente, la relación o conexión de tales Estados con la Convención. En efecto, el artículo 1(1) CV prevé una conexión o relación directa y otra indirecta, siendo cualquie-

\footnotetext{
20 FERRARI (1999) p. 131.

21 Artículo 3. "(1) Se considerarán compraventas los contratos de suministro de mercaderías que hayan de ser manufacturadas o producidas, a menos que la parte que las encargue asuma la obligación de proporcionar una parte sustancial de los materiales necesarios para esa manufactura o producción. 2) La presente Convención no se aplicará a los contratos en los que la parte principal de las obligaciones de la parte que proporcione las mercaderías consista en suministrar mano de obra o prestar otros servicios".

${ }^{22}$ La Convención no define establecimiento. Ferrari, siguiendo la opinión de los autores que comentan la disposición, afirma que nos hallamos en presencia de un establecimiento cuando existe una organización estable de la empresa, de modo que se establezca una vinculación adecuada entre la misma empresa y el Estado en que opera, con tal que esté caracterizado por un efectivo poder autónomo, a lo menos, para negociar el contrato. Véase: FERRARI (1999) pp. 67-68.

23 Véase: Fauba France FDis GC Electronique con Fujitsu Microelectronik GmbH (1992); y comentado en WITZ (1995) pp. 135-139.
} 
ra de ellas suficientes para determinar la aplicación de la Convención ${ }^{24}$. Será directa cuando los establecimientos de ambas partes se encuentran en Estados que son partes de Viena -se habla de Estado contratante- sin interesar que las partes tengan conocimiento de ello. La Convención, que constituye derecho en esos dos Estados, se impone por aplicación del principio de la especialidad sobre la ley que regula el negocio interno. En el caso de Chile, las compraventas que celebren empresas - personas naturales o jurídicas- que tengan su establecimiento en Chile con otra empresa que lo tenga en otro Estado contratante se regirán por la Convención, por ser esta el derecho aplicable, salvo que en el mismo contrato las partes hayan excluido su aplicación.

Sin embargo, la aplicabilidad de la Convención no está necesariamente descartada cuando una o ambas partes ${ }^{25}$ tengan su establecimiento en un Estado que no sea parte de la Convención. Ciertamente, ella igualmente se aplicará cuando las normas de derecho internacional privado conduzcan a la ley de un Estado que sí lo sea ${ }^{26}$. La relación con la Convención es indirecta al producirse por intermedio de un tercer Estado, el designado por la norma de conflicto. Cabe precisar que los Estados, al momento de adherir o ratificar la Convención, podían y pueden evitar que ella sea aplicable por esta relación indirecta, siempre que ellos declaren en ese momento que no quedarán obligados por el artículo 1, (1) letra b). Se trata de la reserva del artículo 95 de la Convención y que ha sido hecha por Canadá27, Eslovaquia, República Checa, China y Estados Unidos de Norteamérica.

Como se ha adelantado, pese a la concurrencia de las condiciones expuestas podrían las mismas partes excluir, expresa o tácitamente, como derecho aplicable la Convención. En este evento, sin perjuicio de la interpretación que pueda hacerse de la cláusula en mención ${ }^{28}$, el operador jurídico -el juez del foro o el árbitro- resolverá el asunto conforme al derecho interno aplicable según la norma de conflicto, ignorando la Convención de Viena.

\footnotetext{
24 Según el art. 1 (1) de la CV, ella se aplica a los contratos de compraventa de mercaderías entre partes que tengan su establecimiento en Estados diferentes: a) cuando esos Estados sean Estados contratantes; y b) cuando las normas de derecho internacional privado prevean la aplicación de la ley de un Estado contratante [letras a) y b)].

25 SCHLECHTRIEM (1986) p. 25.

${ }^{26}$ Como afirma Ferrari, se trata de una solución clásica del derecho internacional privado. FERRARI (1999) p. 90. En el mismo sentido, CASSONI (1982) p. 434.

27 Esta fue la declaración conforme el artículo $95 \mathrm{CV}$ : "Upon accession the Government of Canada declared that, in accordance with Art. 95 of the Convention, with respect to British Columbia, it will not be bound by Art. 1(1)(b) of the Convention".

${ }^{28}$ La doctrina y la jurisprudencia discute el alcance de las cláusulas de sometimiento a un derecho interno, en el que Viena es ley aplicable. La posición mayoritaria estima que esta cláusula no excluiría la aplicación de la Convención, a menos que las partes lo expresen determinantemente. Se requiere, entonces, una exclusión expresa, en el sentido que las partes declaren que el contrato no se regirá por la Convención, sino que por un determinado derecho interno. Véase: Herber (1998) pp. 53 y 54 . Así lo resuelve la Sentencia (2001). En contra: American Biophysics con Dubois Marine Specialties, A/K/A Dubois Motor SPORTS (2006). El Tribunal declaró que el sometimiento al derecho de un Estado contratante de Viena era suficiente para excluir su aplicación.
} 
2. Ámbito material de la Convención de Viena sobre compraventa internacional de mercaderías e integración de lagunas

Luego de haber develado cuándo se aplica Viena, debe darse respuesta a la siguiente pregunta: ¿qué materias quedan sujetas a su normativa?; y con relación a aquellas que no lo están: ¿qué derecho se aplica? Sobre el particular resulta de especial interés el recurso, por un lado, a las disposiciones de los artículos 4 y $5 \mathrm{CV}$; y, por otro, a la del artículo $7 \mathrm{CV}$, párrafo segundo. Los primeros permiten descubrir el ámbito material o sustantivo de este derecho: la Convención regula algunos aspectos de la compraventa internacional, no así otros. Los aspectos excluidos se someten al derecho interno aplicable según el derecho internacional privado ${ }^{29}$. El párrafo segundo del artículo 7 instituye el mecanismo de integración de las materias que, a pesar de pertenecer a su ámbito material, no son resueltas expresamente.

El artículo 4 prescribe que la Convención regula exclusivamente la formación del contrato y los derechos y obligaciones del vendedor y el comprador dimanantes del mismo. La parte II de la Convención regla sobre la formación del contrato (artículos 14 a 24) y la Parte III, "sobre los derechos y obligaciones del vendedor y del comprador" (artículos 25 a 88). Se infiere del precepto que cualquiera otra materia queda fuera del ámbito de la Convención, rigiéndose por el derecho interno determinado por la norma de conflicto. En su segunda parte, la disposición descarta lo relativo a la validez del contrato, o de sus estipulaciones o usos; y los efectos que pudiese producir en la propiedad de las mercaderías vendidas (véase artículo 4, letras a) y b) ${ }^{30}$. Igualmente, conforme al artículo 5, la Convención tampoco se aplica a la responsabilidad del vendedor por la muerte o lesiones corporales causadas a una persona por las mercaderías. Al igual que las anteriores, estas materias se someten al derecho designado por la norma de conflicto del derecho internacional privado ${ }^{31}$. En el primer caso, la Convención no se aplica por la no inclusión de la materia; en el segundo, es la propia Convención la que la excluye dejándola entregada al derecho interno.

Recapitulando, no solo quedan excluidas de Viena las materias a que se refieren los preceptos citados, sino también aquellas que exceden del encabezado del artículo 4 y entre ellas se cuenta la prescripción de las acciones de que son titulares las partes, materia objeto de una Convención de las Naciones Unidas, la de Nueva York del año 1974, incluido su Protocolo modificatorio de $1980^{32}$; Convención que a la fecha no ha sido ratificada por $\mathrm{Chile}^{33}$.

\footnotetext{
${ }^{29}$ Cfr. VÁSQUEZ (2000) pp. 80-82.

30 Pese a que los términos del precepto son categóricos, esta exclusión no es absoluta, sino más bien relativa, ello pensando en su primera parte: "salvo disposición expresa en contrario de la presente Convención". 31 Conviene recalcar que existe una Convención de La Haya del año 1984 sobre derecho aplicable a la compraventa internacional de mercaderías, la que a la fecha no ha sido ratificada por Chile.

32 Sobre el alcance de esta Convención y su implicancia en materia de compraventa internacional y repercusión en los derechos internos, véase: MARTínEZ (1999) pp. 165-183. Sobre la prescripción de las acciones en la compraventa internacional, véase: MASKOW (1992).

$33 \mathrm{La}$ que ha sido ratificada por 19 Estados. Sobre la situación de ella, véase: http://www.uncitral.org/ uncitral/en/uncitral_texts/sale_goods/1974Convention_status.html
} 
No es difícil advertir lo complicado que resulta dibujar el preciso ámbito material o sustantivo de la Convención ${ }^{34}$. En lo que atañe a las materias excluidas no cabe hablar de propiamente de lagunas; sí, en cambio, cuando se trata de cuestiones que pese a estar dentro del referido ámbito material no están expresamente resueltas. En este último caso hay una laguna propiamente dicha y ella debe integrarse de acuerdo al mecanismo previsto por el artículo $7 \mathrm{CV}$, párrafo segundo, debiendo el operador jurídico recurrir a los principios generales en que se apoya la Convención y solo a falta de tales principios podrá aplicar el derecho interno que designe la norma de conflicto ${ }^{35}$. La integración de la laguna por el derecho interno se admite como último recurso, solo así se asegura la autonomía del derecho uniforme. En el caso chileno, si la norma de conflicto le determina como aplicable, a mi entender, hay que recurrir directamente al régimen común y general de la compraventa, contenido en el Título XXIII, "De la compraventa", del Libro IV del Código Civil y a las demás disposiciones de aplicación general en materia de obligaciones de origen contractual del mismo cuerpo legal, sin que sea lícito acudir al Código de Comercio. El derecho de Viena supera la distinción entre contratos civiles y mercantiles; para esta no interesa ni la nacionalidad de las partes ni su condición de comerciantes (artículo 1 (3) CV) y se erige como un ordenamiento especial ubicado normativamente en el mismo plano que la norma del Código de Comercio; ambas ramas especiales se dirigen al mismo tronco común: el derecho civil. Por ende, si la Convención -en tanto derecho especial en ella contenido- no resuelve expresamente una materia, se aplicará, en último término, el derecho civil. Naturalmente, esta opinión podría discutirse argumentando que en el ordenamiento jurídico chileno subsiste la distinción entre contrato civil y mercantil y hay duda que si uno debe ubicar a la compraventa internacional, lo hará en la segunda clase de contratos, y, consiguientemente, siguiendo esa lógica, el derecho supletorio sería el del Código de Comercio y supletoriamente el del Código Civil. A mi juicio, el derecho de la compraventa internacional es una rama especial, al igual que el derecho comercial y como tal se integra por el derecho civil, al que convergen ambas ordenaciones.

\footnotetext{
${ }^{34}$ La delimitación precisa entre las materias que están dentro del ámbito de aplicación de la CV y las que no lo están, fuera de los casos en que hay absoluta claridad (artículos 4 y $5 \mathrm{CV}$ ), es sumamente compleja. Así lo reconocen: Ulrich (1995) p. 4; Herber (1998); GARro (1995) pp. 1149-1990 y p. 1156).

35 En este derecho prevalece la autointegración de su normativa, por sobre su heterointegración. En efecto, la Conferencia de las Naciones Unidas, a la hora de decidir cómo se integran las lagunas que pudiese presentar la Convención, prefiere la aplicación de ella misma, ya no entendida como norma jurídica específica, sino como principio de derecho en que ella se apoya o fundamenta. El recurso al derecho interno aplicable conforme la norma conflictual solo está autorizado cuando no sea posible encontrar la solución en los principios en los que se inspiran sus preceptos particulares. Por esta razón, el párrafo (2) del art. 7 dispone que las materias no resueltas - pero que se hallan dentro del ámbito de aplicación de la Convención - se someterán a los principios generales en los que esta se funda, o inspira. A falta de dichos principios, el operador jurídico -entiéndase el juez o árbitro- podrá resolverlas con arreglo a la norma de derecho interno, aplicable conforme la norma de conflicto. Véase: VIDAL (2003a) pp. 457-491 y VIDAL (2003b) pp. 993-1040.
} 


\section{SECCIÓN II. EL INCUMPLIMIENTO CONTRACTUAL Y LOS REMEDIOS DE QUE DISPONE EL ACREEDOR CON ÉNFASIS EN LA RESPONSABILIDAD POR DAÑOS}

\section{A) LA OBLIGACIÓN CONTRACTUAL, SU INCUMPLIMIENTO Y SUS EFECTOS EN LA CONVENCIÓN DE VIENA}

\section{La obligación en el derecho uniforme}

El sistema de remedios por incumplimiento contractual descansa en una especial construcción del contrato, nueva y distinta de la existente en los ordenamientos jurídicos internos de los Estados contratantes pertenecientes ya sea al sistema del derecho civil continental o al del Common $\mathrm{Law}^{36}$. De esta construcción resulta un ensanchamiento de la obligación contractual llevada hasta sus últimas consecuencias, en tanto el contrato representa para el acreedor una garantía de satisfacción de su interés contractual, quien contrata precisamente en consideración a esa satisfacción. El deudor de Viena no se obliga a la ejecución de deberes de conducta predefinidos e individuales o fraccionados, sino a la ejecución de toda aquella actividad que sea razonable esperar de él -habida cuenta las circunstancias del caso- para alcanzar el fin último perseguido: la satisfacción del interés del acreedor. Así, por ejemplo, el vendedor al obligarse garantiza la entrega oportuna de mercaderías y de los documentos relacionados con ellas, todo ello conforme al contrato; y la transferencia de su propiedad, libre de cualquiera pretensión de terceros sobre las mismas (artículos 30 y 35 de la CV).

Esta mayor extensión de la obligación del deudor, entendida como garantía, se aprecia nítidamente en las disposiciones sobre la conformidad de las mercaderías (Parte III, Sección II, artículos 35 y siguientes). Según estas disposiciones, las mercaderías deben ser aptas para los usos a que ordinariamente se destinen otras del mismo tipo, o para el uso especial, que expresa o tácitamente, se haya hecho saber al vendedor en el momento de la celebración del contrato (artículo 35, (2), letras a) y b) CV). Aquí, no obstante haberse entregado las mercaderías, si ellas no son conformes, hay incumplimiento contractual y la Convención pone a disposición del comprador los remedios comunes a todo incumplimiento, salvas algunas particularidades dadas para la falta de conformidad. Si se intenta ubicar a la falta de conformidad dentro de los efectos del incumplimiento del Código Civil, ella se vincula con los vicios redhibitorios (incumplimiento de la obligación de garantía) cuyos efectos son los que especialmente regula la ley y que van desde la acción redhibitoria (artículo 1857 Código Civil) a la indemnización de daños sometida a las reglas generales sobre los efectos del incumplimiento (artículo 1861 Código Civil) pasando por la acción de rebaja del precio (artículo 1867 y 1869 Código

${ }^{36}$ No puede dejar de reconocerse la fuerte influencia del Common Law en esta construcción del contrato y de la obligación de que este nace. Por todos: véase MORALEs (1998) pp. 289-292. 
Civil ${ }^{37}$. Viena no recoge el instituto de los vicios redhibitorios y sus particulares efectos, estos y aquellos son absorbidos por la figura del incumplimiento y, en particular, por la noción de la falta de conformidad de las mercaderías y los remedios que ella pone a disposición del comprador afectado.

Esta idea de obligación-garantía determina que la Convención imponga al deudor (vendedor o comprador) una responsabilidad por daños objetiva de carácter casi absoluta, caracterizada porque actúa y se desenvuelve al margen de la culpa (objetivada) y porque prevé escasas posibilidades de exoneración ${ }^{38}$. Se habla de una responsabilidad estricta.

La responsabilidad por incumplimiento se presenta como un mecanismo de reparto de riesgos. El deudor al contratar garantiza al acreedor la satisfacción de su interés; y si ello no ocurre por su incumplimiento, será responsable por los daños razonablemente previsibles al tiempo del contrato. El deudor pecha con dos riesgos, que el incumplimiento se produzca y que este cause daños. La explicación de la atribución de responsabilidad se halla en la idea de las esferas de control del deudor. La ley presupone que el deudor asume el riesgo del incumplimiento desde la celebración del contrato y por ello debe administrarlo y controlarlo. Siendo así, si el incumplimiento se produce, es porque el deudor no controló el riesgo de que este tuviese lugar y, por ello, le atribuye responsabilidad, pero solo por los daños previsibles. Este reparto de riesgos, sea por la aplicación de la regla de la exoneración del artículo 79 (1) CV, sea por la regla de mitigación del artículo 77, excluye de la indemnización daños aquellos que, pese a su previsibilidad, el acreedor habría podido evitarlos. Sobre estas reglas me referiré in extenso más abajo.

\section{El incumplimiento contractual}

A partir del concepto amplio de obligación a que se hace mención se llega indefectiblemente a la conclusión que el deudor -sea el vendedor o el comprador- no está llamado a cumplir una o varias obligaciones fraccionadas, sino el contrato entendido como un todo; se reemplaza la idea de incumplimiento de obligaciones contractuales por la del incumplimiento del contrato ${ }^{39}$.

\footnotetext{
${ }^{37}$ No existe acuerdo en la doctrina sobre si la acción de indemnización del artículo 1861 del Código Civil es una acción accesoria de la resolutoria o de rebaja del precio, o una independiente con plazo propio de prescripción, la general de los 5 años.

38 El profesor Morales Moreno reconoce que uno de los rasgos caracterizadores de la responsabilidad contractual de la Convención es la utilización de un concepto amplio de incumplimiento que permite integrar todas las manifestaciones de la insatisfacción del interés del acreedor. MORALES (1997) pp. 4 y 8.

39 Ello se manifiesta claramente en la noción de incumplimiento esencial que según el artículo 25 CV es aquel que causa al acreedor un perjuicio tal que le priva sustancialmente de lo que tenía derecho a esperar en virtud del contrato, a menos que el deudor incumplidor no hubiera previsto tal resultado y que una persona razonable de su misma condición no lo hubiera previsto o podido prever en igual situación. Cuando el incumplimiento lesiona el interés del acreedor en esta medida, no cabe duda que ya no tiene justificación mantener el contrato y por ello se le faculta al acreedor para resolverlo.
} 
La Convención recoge un concepto amplio de incumplimiento contractual, entendido como sinónimo de cualquiera desviación del programa inicial e ideal de prestación convenida por las partes e integrado por la ley uniforme, que produzca la insatisfacción del interés contractual del acreedor. Entonces, el incumplimiento abraza cualquiera discordancia entre lo prometido y debido por el deudor -sea el vendedor o el comprador-y lo verdaderamente ejecutado; quiere decir que el incumplimiento va desde la más absoluta pasividad del deudor (falta de cumplimiento) hasta su actividad defectuosa (cumplimiento imperfecto) ${ }^{40}$.

El incumplimiento se concibe como un hecho objetivo consistente en cualquiera infracción de los contenidos de la regla contractual y el efecto que produce en la situación del acreedor es la de lesionar su interés obstando su satisfacción plena. Este incumplimiento produce sus efectos al margen de la culpa o negligencia del deudor que lo comete.

En la Convención la conducta del deudor se mide de acuerdo a un estándar más exigente que el del derecho civil continental. Se abandona el modelo del hombre diligente y se adopta el de una persona razonable ${ }^{41}$.

El deudor incumple el contrato cuando se produce esta desviación o infracción al programa, independientemente de la valoración que pueda hacerse de su conducta, y los efectos que el incumplimiento produce no implican un reproche de dicha conducta, sino simplemente una reacción frente a la objetiva insatisfacción del interés del acreedor que debe ser remediada. Ello no quiere decir que el deudor no pueda excusarse de cumplir en algunos supuestos y así liberarse de responsabilidad. Como se ha dicho, el deudor puede quedar exonerado de responsabilidad cuando la causa de su incumplimiento fue un impedimento ajeno a su esfera de control. Este impedimento no extingue la obligación, solo suspende su exigibilidad; y no afecta el ejercicio de los restantes remedios que presuponen igualmente el incumplimiento, como la resolución, la rebaja del precio, o la sustitución o reparación de las mercaderías. Así fluye del párrafo 5 del artículo 79 de la Convención ${ }^{42}$. Lo expresado se recoge por los PECL, los que al definir el incumplimiento expresan: "incumplimiento significa cualquier incumplimiento de la obligación contractual, tanto si es excusable como si no lo es, e incluye el cumplimiento retrasado, el cumplimiento defectuoso y la infracción de deberes de cooperación para alcanzar la plena efectividad del contrato" (Art. 1301 (4) "Significado de los términos"). Como afirma Roca, Díez-Picazo y Morales Moreno, en los principios hay incumplimiento incluso en los casos en que exista una causa de exoneración de las previstas en el artículo

40 Morales Moreno expresa que el incumplimiento contractual se concibe como "incumplimiento de contrato" o, mejor, como "insatisfacción del interés", derivado del mismo, agregando que el incumplimiento abarca todos los contenidos de la vinculación contractual del vendedor o del comprador. MORALES (1997).

41 Véase: VidAL (2003).

42 En lo que concierne al remedio del cumplimiento específico propiamente dicho, si bien el citado precepto se refiere en general a los derechos del acreedor, en mi opinión, y así se explicará más adelante, la exoneración también incidiría en el cumplimiento específico, cuyo ejercicio quedaría suspendido mientras subsista la razonable insuperabilidad de las consecuencias del impedimento. Se aplica por extensión analógica el párrafo 1 del citado artículo $79 \mathrm{CV}$. 
8108, pues las causas de exoneración no excluyen el uso de todos los remedios del incumplimiento, sino solo algunos de ellos ${ }^{43}$.

\section{Los remedios de que dispone el acreedor afectado por el incumplimiento}

Los efectos del incumplimiento constituyen mecanismos objetivados de protección del interés del acreedor, cuya funcionalidad pende fundamentalmente de que se produzca el hecho del incumplimiento del contrato. A estos mecanismos se les denomina remedios y corresponden a los derechos o acciones de que dispone el acreedor en caso de incumplimiento para la realización de su interés. En el Common Law, la expresión general remedios se define como aquellos medios por los cuales se ejecuta un derecho o se evita, compensa o indemniza su violación. Y, en particular, los remedios por incumplimiento son aquellos derechos o facultades que la ley o el contrato confiere a la parte afectada por el incumplimiento, cuyo ejercicio depende del incumplimiento de la otra parte contratante y de la concurrencia de su supuesto de hecho específico ${ }^{44}$.

Producido el incumplimiento, la Convención pone a disposición del acreedor agraviado un abanico de remedios, entre los cuales podrá optar, según mejor le convenga, y en la medida que concurra su supuesto específico. Se instaura un sistema unitario de remedios articulado a partir del incumplimiento contractual, desapareciendo, por ejemplo, las acciones edilicias [redhibitoria o actio quanti minoris], propias del sistema de derecho civil y aquellas que tienen su fundamento en los vicios del consentimiento; acciones estas que son absorbidas por los remedios comunes y generales que Viena prevé y que pone a disposición del acreedor en caso de incumplimiento ${ }^{45}$.

La Convención articula los derechos y acciones del acreedor en caso de incumplimiento a través de un sistema unitario cuyo presupuesto de hecho básico y genera es el incumplimiento de cualquiera de las obligaciones establecidas por el contrato o la Con-

\footnotetext{
43 Díez-PiCAZo et al. (2002) p. 322.

${ }^{44}$ CAmpbell (1990), p. 1294. Debemos tener en cuenta que en el Common Law se distingue entre Equity remedies o relief y Legal remedies. Los primeros son "That species of relief sought in a court with equity powers as, for example, in the case of one seeking an injuction or specific performance instead of money damages"; y equity es "The justice admnistered according to fairness as contrast with the strictly formulated rules of common law. It is based on a system of rules and principles which originated in England as an alternative to the harsh rules of common law and which were based on what was fair in a particular situation". La segunda categoría se refiere a "remedy available, under the particular circumstances of the case, in a court of law, as distinguished from a remedy available only in equity". Se debe tener presente que, desde un punto de vista procesal, esta distinción no tiene mayor importancia, ya que bajo las reglas de Procedimiento Civil existe una sola forma de acción conocida como civil action. Esta es definida: "Action brought to enforce, redress, or protect private rights". Y por civil remedies se entiende: "The remedy afforded by law to a private person in the civil courts in so far as his private and individual rights have been injured[...]".

45 El profesor Morales Moreno considera como uno de los rasgos característicos de la responsabilidad contractual de la Convención, el que en ella se unifica y articula armónicamente el sistema de remedios fundados en el incumplimiento contractual. La utilización de estos remedios estaría justificada por el incumplimiento de cualquiera de las obligaciones del vendedor o del comprador. Opina que, como consecuencia de esta característica, en este sistema desaparecen las acciones de saneamiento [por evicción, por cargas ocultas, por vicios ocultos], y las fundadas en los vicios del consentimiento, cubriendo su función los remedios del incumplimiento. MORALES (1997) pp. 4 y 14.
} 
vención. Los artículos 45 y 61 de la Convención regulan en general los remedios por el incumplimiento del vendedor y del comprador, respectivamente. Estas disposiciones enuncian los derechos y acciones (remedios) de que dispone el acreedor agraviado con el incumplimiento de "cualquiera de las obligaciones" que le incumba al deudor conforme al contrato o a la Convención. La regulación particular de cada remedio está contenida, o en las disposiciones pertinentes de aplicación exclusiva al incumplimiento del vendedor (Parte III, Capítulo I, sección III, Derechos y acciones en caso de incumplimiento del contrato por el vendedor) o del comprador (Parte III, Capítulo III, sección III, Derechos y acciones en caso de incumplimiento del contrato por el comprador); o en las disposiciones de común aplicación a las obligaciones del vendedor y del comprador (Capítulo V, artículos 71 y ss).

$\mathrm{Al}$ regular de esta forma el incumplimiento y sus efectos se evita cualquier laguna o vacío que impida la aplicación de los remedios a supuestos de incumplimiento no previstos expresamente ${ }^{47}$. El concepto amplio de incumplimiento se hace acompañar por un sistema general de remedios que la Convención pone a disposición del acreedor afectado.

Se implanta un sistema unitario de remedios disponibles para el incumplimiento de cualquiera de las obligaciones que le incumba al deudor. Ante esta pluralidad de remedios disponibles, al acreedor pertenece la facultad de optar libremente por el ejercicio de aquel remedio que resulte más adecuado para la superación de la insatisfacción de su interés contractual.

Debo precisar que si bien la Convención regula genéricamente los remedios por incumplimiento del contrato, cada uno tiene su propia ordenación que establece los requisitos que autorizan su ejercicio para el caso concreto. El único remedio general y común a todo incumplimiento es el de la responsabilidad civil por daños (indemnización de daños), cuyo único límite es la causa de exoneración del artículo $79 \mathrm{CV}$, sin perjuicio de las normas delimitadoras de la misma (Artículos 74 segunda parte y 77 , ambos de la CV). Y esta indemnización de daños puede ejercerse, sea exclusivamente, sea en forma complementaria con cualquiera de los otros remedios. La propia normativa de Viena así lo reconoce. Después de establecer el catálogo genérico de remedios, los regula específicamente, a propósito del incumplimiento del vendedor y del comprador. Además, y como muestra que la indemnización de daños es el remedio común y de general aplicación, las disposiciones comunes a las obligaciones del vendedor y comprador, disponen sobre la atribución y extensión de la responsabilidad del deudor incumplidor, incluyendo la exoneración de la misma (Capítulo IV, artículos 71 y siguientes).

Uno de los principios en que se apoya el sistema de la Convención es el de la conservación del contrato que se manifiesta principalmente en el reconocimiento del cumplimiento específico y la indemnización de daños como remedios de general procedencia y en las limitaciones al ejercicio de la resolución y de la sustitución de las mercaderías; pero también, y con mayor fuerza, en el derecho a subsanar el incumplimiento. Según el artículo 48 de la Convención, el vendedor tiene derecho a subsanar el

47 Esto no es sino una respuesta a la especial construcción del contrato y la obligación contractual. Viena recoge esta técnica legislativa del UCC. norteamericano. 
incumplimiento a su propia costa siempre que con ello no se cause una demora e inconvenientes excesivos para el comprador afectado por el incumplimiento o incertidumbre sobre del reembolso de los gastos anticipados por esta última parte. Este derecho afecta el ejercicio de cualquier remedio mientras se encuentre pendiente el plazo para la subsanación, sin perjuicio del derecho a la indemnización por los daños que haya causado el incumplimiento. Este derecho a subsanar el incumplimiento lo define Ángel López López como "la facultad del vendedor para realizar todas las actuaciones necesarias para que la prestación comprometida, y no ejecutada de acuerdo con el programa contractual, se ajuste a este y pueda satisfacer el interés del comprador" ${ }^{38}$. Este derecho, desde luego, entra en una abierta pugna con la facultad resolutoria y el derecho a pedir la sustitución de las mercaderías cuando el incumplimiento que se trata de subsanar es un incumplimiento esencial ex artículo 25 de la Convención. A primera vista, el derecho del artículo 48 prevalece respecto de los otros, sin embargo, a mi juicio la solución a este conflicto viene dada por las propias reglas en la que descansa el sistema de remedios de Viena. Existe un conflicto entre estos dos derechos; sin embargo, como se verá más adelante, otro principio en que se inspira el sistema es el de la gestión razonable de los remedios por el incumplimiento por parte del acreedor afectado. Pues bien, si el vendedor hace uso de su derecho a la subsanación del incumplimiento, comunicándolo al comprador, este solo podrá rechazar la subsanación, fundándose, o en las circunstancias objetivas previstas por el precepto, esto es, que la subsanación cause una demora o inconvenientes excesivos o incertidumbre acerca del reembolso de los gastos anticipados; o que el incumplimiento que se pretende subsanar es esencial y, por consiguiente, que la actividad del vendedor no es idónea para lograr la satisfacción de su interés contractual en tanto el mencionado incumplimiento le privó definitivamente de aquello a lo que tenía derecho a esperar en virtud del contrato (artículo $25 \mathrm{CV}$ ). Si el rechazo a la subsanación es infundado, quien habrá incumplido el contrato es el propio comprador y, por esta razón, incurrirá en responsabilidad para con el vendedor afectado ${ }^{49}$.

\section{La cargas impuestas al acreedor afectado por el incumplimiento ${ }^{50}$ y la gestión} razonable de sus efectos ${ }^{51}$

El estándar de lo razonable modela la conducta del acreedor en el ejercicio de los remedios por el incumplimiento. El acreedor debe observar una razonable gestión de los

\footnotetext{
48 LÓPEZ (1998) p. 427.

49 En la doctrina, Ángel López López apunta que esta solución es más "adecuada a un equilibrado balance de intereses, pues supone un estímulo al correcto cumplimiento, y no otorga indebidas ventajas al causante del incumplimiento; empero, no debe olvidarse que el ejercicio de la resolución debe adecuarse a la buena fe (art. 7), lo que ha de impedir el recurso abusivo a aquella, que, cierto es, tiene un claro carácter de excepcional dentro de la economía del Convenio" (LÓPEZ, 1998, p. 429).

$50 \mathrm{El}$ origen de las cargas se halla en el derecho procesal y ellas significan la necesidad de realizar determinados actos para evitar desventajas de carácter procesal. La no-realización de la conducta que impone la carga, no es propiamente algo contrario a derecho, sino un imperativo del propio interés del llamado a observarla. Véase: GOLDSCHMidT (1983) pp. 203 y ss.; Pietro-CASTRO (1982) pp. 71-72; Almagro et al. (1986) pp. 186-189.

${ }^{51}$ Sobre la gestión razonable de los efectos del incumplimiento que pesa sobre el acreedor, su alcance y las diversas cargas contractuales impuestas por la CV, véase: VIDAL (2005).
} 
efectos del incumplimiento, que se traduce en la imposición de cargas de comunicación y de conducta material que debe ejecutar. He aquí una de las más importantes manifestaciones del principio de lo razonable en Viena ${ }^{52}$.

El sistema de remedios de la Convención se muestra como excesivamente protector del interés del acreedor y muy severo con el deudor incumplidor. Sin embargo, ello es más aparente que real. En la Convención ambas partes deben someter su conducta a las exigencias del estándar de lo razonable. Se protege tanto el interés del acreedor como el del deudor incumplidor. A este se le garantiza que el acreedor, a pesar del incumplimiento, se comportará como lo haría una persona razonable en lugar y circunstancias. Se logra así la construcción de un sistema equilibrado.

El acreedor debe contribuir, con su conducta, a que los efectos del incumplimiento sean lo menos gravosos para el deudor incumplidor. Se trata de evitar que los drásticos efectos del incumplimiento se incrementen a causa de una actitud arbitraria, especulativa, antojadiza o simplemente de pasividad de parte del acreedor. Para alcanzar este objeto, como se ha explicado, la Convención impone al acreedor unas cargas de conducta ${ }^{53}$.

El acreedor deberá hacer un uso razonable de los remedios que la CV pone a su disposición, en términos que si no lo hace, bien se le priva del derecho a invocar el incumplimiento, bien se le limita la protección que en principio le confiere ante el incumplimiento de su deudor.

\section{a) Las cargas contractuales del acreedor en la Convención ${ }^{54}$}

La relación jurídica obligatoria a que da lugar la compraventa internacional es muy compleja, ella impone no solo obligaciones al deudor que se traducen en el correlativo derecho del acreedor, sino cargas que afectan a este último ${ }^{55}$. El derecho de crédito de que es titular el acreedor constituye una situación jurídica, compuesta, ciertamente, de facultades o derechos, pero también de cargas contractuales ${ }^{56}$.

\footnotetext{
52 El principio de lo razonable, entendido como "gestión razonable de las consecuencias del incumplimiento" se recoge de: FORTIER (1996) pp. 368 y ss. El autor habla de la "La gestion raisonnable des conséquences de l'inexécution" y expresa que la razonabilidad aparece, desde esta perspectiva, como una noción "pivote": los medios empleados por el acreedor dentro del marco de su "deber de actuar" se aprecian de acuerdo al estándar jurídico de lo razonable, lo que se traduce en que los daños e intereses demandados por este no deben sobrepasar los límites de lo razonable. En el mismo sentido, aunque sin emplear el término gestión razonable: BERLINGIERI (1981) pp. 329-331.

53 Berlingieri reconoce expresamente que la Convención impone ciertas cargas al acreedor afectado por el incumplimiento, dentro de las cuales cita: a) la carga del art. 77; b) la del art. 75 referida a la celebración de una operación de reemplazo; c) la carga de denuncia del art. 39 (1); y, finalmente, c) la carga de conservar las mercaderías de los artículos 85, 86, 87 y 88. En los Comentarios de la Secretaría del Proyecto de 1978 se reconoce implícitamente que al acreedor se le imponen cargas o deberes a pesar de verse afectado por el incumplimiento. UNCITRAL, Secretariat Commentary CISG., art. 73, par. 2, n. 1.

54 Para un estudio de las cargas del acreedor en el derecho privado español y comparado, véase: CABANILLAS (1988).

55 La Convención también impone cargas al propio deudor, como la de su art. 79(4), que exige notificar al acreedor, dentro de un plazo razonable, sobre el impedimento que afecta el cumplimiento.

56 Cfr. MASKOW (1992) par. 2.3. El autor se refiere a las cargas contractuales en términos de "obligaciones secundarias”; De CASTro (1985) p. 39; Díez-PiCAZo (1964) pp. 349 y ss; y Díez-PiCAzO (1996) pp. 377 y ss.
} 
Una carga contractual es la imposición legal, o convencional, de una determinada conducta, cuyo incumplimiento no otorga al perjudicado una pretensión encaminada a exigir su observancia, empero, ubica a su titular ante ciertas desventajas jurídicas, como la pérdida o la reducción de derechos ${ }^{57}$. Como acertadamente afirma el profesor DíezPicazo, la carga no constituye una obligación, sino un "tener que" que actúa como base de un posterior "poder ser". Así, el acreedor afectado que invoca el incumplimiento, reclamando la indemnización de los daños causado por este, debe adoptar las medidas que sean razonables para evitar, o aminorar, las pérdidas (tener que), y, solo de este modo, podrá obtener la completa indemnización previsibles al tiempo del contrato (poder ser), sin que ella sea sometida a reducción por aplicación del artículo 77 CV 58 . La carga es una conducta que el acreedor ha de observar para adquirir un derecho o ejercitarlo o bien obtener un cierto beneficio, siendo libre para llevarla a cabo, o no; pero si no la observa se produce un efecto desfavorable para sus intereses ${ }^{59}$.

Junto con asignar la carga, la CV prevé el efecto de su inobservancia, el que no se traduce en el derecho a exigir su cumplimiento o una indemnización de daños o cualquiera otro remedio de los previstos ${ }^{60}$, sino en la privación de un derecho del titular de la misma o de su ejercicio, o simplemente en su limitación; o bien otros diversos que prevea la convención de las partes. Ello es lo que diferencia a una carga contractual de una obligación en sentido técnico ${ }^{61}$.

Así, por ejemplo, cuando el comprador no denuncia la falta de conformidad dentro de un plazo razonable, se le priva del derecho a invocar ese incumplimiento $y$, consiguientemente, del ejercicio de cualquier remedio, incluida la indemnización de daños. La pasividad del acreedor se interpreta como señal, o indicio, de aceptación de las mercaderías, en tanto una persona razonable, en su lugar, la hubiese denunciado dentro de dicho plazo.

\section{b) Tipos de cargas contractuales del acreedor en la CV}

En la Convención se distinguen dos tipos de cargas contractuales, las de comunicación y las de realización de una conducta material. Las primeras imponen al acreedor

\footnotetext{
57 Las normas que asignan cargas contractuales se denominan disposiciones ordenatorias y constituyen una categoría intermedia entre las normas imperativas y las dispositivas; y ellas se caracterizan porque subordinan la adquisición o el ejercicio de ciertos derechos a la observancia de ciertas conductas, pudiendo no observarse sin que de ello se siga la aplicación de una sanción, en cuanto a la imposición por la fuerza de la conducta en que ella consista. Cfr. MESSineo (1952) p. 34; y CABANiLlas (1988) p. 35.

58 También, según el art. $39 \mathrm{CV}$, el comprador que denuncia dentro de un plazo razonable la falta de conformidad de las mercaderías (tener que), podrá invocar dicho incumplimiento y ejercitar cualquiera de los remedios que la Convención pone a su disposición (poder ser).

59 Cfr. Galgano (1983) p. 23.

60 Cfr. SOlER (1998).

${ }^{61}$ Como afirma Messineo, la obligación cumplida por el deudor tiende a satisfacer el interés negocial del acreedor; en cambio, la carga observada por el acreedor, en general, satisface su propio interés, toda vez que no se ve expuesto a las consecuencias previstas para su inobservancia, Messineo (1952) p. 34. Por su parte, Betti explica que hay que mantener la antítesis conceptual entre la obligación, a la que en caso de incumplimiento se sigue una responsabilidad del deudor; y la carga, a la que corresponde la autorresponsabilidad en caso de inobservancia. BETTI (1953) p. 92.
} 
el deber, sea de denunciar el incumplimiento del deudor, sea de anunciar sobre las pretensiones, o remedios, de que hará uso. Las segundas, en cambio, exigen del acreedor la realización de una conducta material que consiste en la adopción de medidas razonables, atendidas las circunstancias, tendientes a evitar, o aminorar, las consecuencias del incumplimiento.

i) Las cargas contractuales de comunicación. En la CV no son pocas las disposiciones que exigen al acreedor la denuncia del incumplimiento o la comunicación sobre la pretensión de que harán uso, bajo el apercibimiento de privarle el derecho a invocar el incumplimiento o del ejercicio del remedio de que se trate ${ }^{62}$. Al acreedor se le traza el camino que debe seguir en caso de incumplimiento. Dentro de las cargas de comunicación es posible distinguir dos clases, la de denuncia del incumplimiento (artículos 39 y $43 \mathrm{CV})^{63}$ y la de anuncio sobre el remedio de que hará uso el acreedor (artículo 46 (2) y (3) CV; y los artículos 49 (2) a) y b) y 64 (2) b) CV).

El artículo $27 \mathrm{CV}$ establece la regla general sobre los efectos de las comunicaciones que se hagan las partes. Según el precepto citado, si una parte debe hacer una comunicación por aplicación de las disposiciones de la Parte III de la Convención y la hace por medios adecuados a las circunstancias, las demoras, o errores que puedan producirse en su transmisión o el hecho que no llegue a destino, no le privan del derecho a invocarla ${ }^{64}$. Y se limita a las comunicaciones de esa parte de la Convención porque cuando se trata de aquellas que tienen lugar en la formación del contrato, el riesgo de la transmisión pertenece al que la hace; rige la regla de la recepción (artículo $18 \mathrm{CV}$ ) y no la de la expedición del artículo 27 . El riesgo de la transmisión de la comunicación es de cargo del deudor incumplidor. La relevancia de la disposición reside en que se entiende que el acreedor realiza la conducta en que consiste la carga, cuando despacha o expide la comunicación, siendo indiferente cuándo ella llega a su destinatario.

El artículo 27 contiene una regla muy flexible al conformarse con que la comunicación se haya hecho por medios adecuados a las circunstancias ${ }^{65}$, sin embargo, ella puede dar lugar a importantes problemas probatorios, pues no debe olvidarse que quien invoca la comunicación -el acreedor- no solo deberá probar el hecho mismo de la comunicación, sino también que ella se hizo por medios adecuados

62 Berlingieri (1958) pp. 329-331; KAROllus (1995) p. 70.

63 El art. 89 del Libro 6 del Nbw. neerlandés, siguiendo el modelo de la Convención, dispone: "The creditor no longer invoque a defect in the prestation if he has not complained to the debtor promptly after he has discovered or should reasonably have discovered the defect". Y su art. 24, en los mismos términos que el art. 39 CV., prescribe: "The buyer may be longer invoke the fact what has been delivery does not conform to the contract, unless he has notified the seller thereof within a reasonable period after he has or reasonably should have discovered this".

64 El profesor Morales Moreno expresa que la regla general de la que se habla es que siempre que el comprador haya elegido los "medios adecuados a las circunstancias", el riesgo de la transmisión de la comunicación lo soporta su destinatario. Si se cumple con esa exigencia, la comunicación se tiene por hecha. MORAles (1998) p. 340.

${ }^{65}$ Cfr. SCHWENZER (1998). 
atendidas las circunstancias. Por este motivo, un acreedor razonable deberá preconstituir la prueba de haber despachado la noticia y de los medios que empleó66 Si no logra acreditar estas circunstancias, se entenderá que no cumplió con la carga de comunicación y, consiguientemente, quedará expuesto a las consecuencias negativas que de ello se sigue.

ii) Cargas contractuales de conducta material. En la Convención se identifican tres disposiciones concretas que imponen al acreedor esta clase de cargas. Los artículos 77, 85 y 86 exigen la adopción de medidas que sean razonables, atendidas las circunstancias, sea para evitar, o mitigar, las pérdidas derivadas del incumplimiento; sea para la conservación de las mercaderías cuya entrega no se materializó, evitando su pérdida, o deterioro. Estas cargas son la de mitigación de las pérdidas (artículo $77 \mathrm{CV}$ ) ${ }^{67}$ y la de conservación de las mercaderías (artículos 85 a $88 \mathrm{CV})^{68}$. Más abajo me ocuparé de la carga de mitigar las pérdidas y de sus efectos en materia de indemnización de daños y respecto del sistema de remedios en general.

Todas estas cargas que impone la Convención al acreedor afectado por el incumplimiento contractual, son simplemente una muestra de que para el derecho uniforme no solo el deudor debe comportarse conforme el estándar de conducta de lo razonable, también debe hacerlo el propio acreedor, quien al enfrentarse a un supuesto de incumplimiento debe realizar una gestión razonable de los remedios que la ley pone a su disposición ${ }^{69}$.

En síntesis, la gestión razonable se resuelve en que la CV exige al acreedor la observancia de ciertas cargas contractuales una vez producido el incumplimiento. Con ello se persigue evitar que el acreedor, en el ejercicio de sus derechos y acciones (artículos 45 y $61 \mathrm{CV}$ ) actúe vulnerando el estándar de lo razonable. La CV sanciona cualquier conducta del acreedor que se aleje de ese estándar, sea privándole de protección, sea limitando sus efectos jurídicos.

\section{Principios que rigen la responsabilidad por daños en Viena}

Como se ha expresado, en la Convención de Viena la responsabilidad se articula a partir del mero hecho del incumplimiento, al margen de la consideración de la culpa contractual del deudor u otro reproche de conducta. Ella instaura un sistema objetivado con limitadas posibilidades de exoneración; se habla de una responsabilidad objetiva y estricta. El deudor es responsable, a menos que pruebe que el incumplimiento se debió a un impedimento que estaba fuera de su razonable control. En razón de la rigurosidad de la regla de atribución de responsabilidad, adquieren especial relevancia las normas sobre

\footnotetext{
66 "By virtue of Article 27 is suffices that the declaration is dispatched within a reasonable time. The buyer must be prove that the declaration was dispatched within that time" (HUBER, 1998, par. 50).

67 Sobre la carga de mitigar las pérdidas, véase principalmente: SOlER (1998a) pp. 621 y ss.; y SOLER (1998b) pp. 61 y ss; STOLL (1998) pp. 585 y ss; KNAPP (1987) pp. 559 y ss.

68 Sobre la carga de conservar las mercaderías, véase especialmente: BARRERA (1987) pp. 613 y ss; EBERSTEIN (1998) pp. 666 y ss; HONNOLd (1991) pars. 454 y ss; y MONTES (1998).

${ }^{69}$ Sobre el estándar de lo razonable y sus funciones en la Convención, véase: VIDAL (2003).
} 
extensión de la indemnización, dado que, frente a la imposibilidad de acreditar una causa que excluya la atribución de responsabilidad, al deudor solo le quedará ampararse en tales normas para intentar reducir la responsabilidad que le viene impuesta por el solo hecho del incumplimiento. A partir de tres principios básicos, implícitos en las disposiciones de la Convención de Viena, es posible la construcción de un sistema nuevo de responsabilidad, distinto a los vigentes en el derecho interno tradicional, cualquiera sea la familia legal a que pertenezcan.

a) Principio de la controlabilidad del riesgo del incumplimiento. En la Convención, como ya se indicado, los remedios por el incumplimiento y, en especial, el de la indemnización de daños, actúan al margen del criterio de la culpa contractual. El deudor responde por el hecho de haber incumplido y esta responsabilidad solo se excluye si el incumplimiento tuvo su causa en un impedimento que estaba fuera de su razonable control. Sin embargo, la exoneración no afecta el ejercicio de los remedios contractuales de que dispone el acreedor, distintos al de la indemnización de daños. El acreedor puede hacer uso de ellos a pesar que el deudor esté liberado de su obligación de indemnizar. Este principio se deduce del artículo 79 $\mathrm{CV}$ y se resuelve en la máxima que todo incumplimiento tiene su causa en la realización de un riesgo inserto en la esfera de control del deudor, salvo, claro está, que rinda prueba en contrario.

b) Criterio de la razonable previsibilidad de los daños que causa el incumplimiento. Habiéndose establecido la atribución de responsabilidad, cobra relieve la noción de daño indemnizable y su extensión. En esta materia, la regla es la reparación integral, comprendiéndose en ella todos los daños patrimoniales que causa el incumplimiento. Sin embargo, la excepción se asienta en el criterio de la razonable previsibilidad de las pérdidas en el momento de la celebración del contrato. En tal sentido, la extensión de la indemnización se identifica con el denominado ámbito de protección del contrato que actúa tanto a favor del acreedor como del deudor; ámbito que queda delimitado desde su celebración. Los daños que exceden ese ámbito, por imprevisibles al tiempo de la celebración del contrato, se excluyen de la indemnización. Y digo que actúa a favor del acreedor porque a él se le asegura desde un principio la indemnización de ciertos daños, los previsibles; y del deudor, porque desde ese mismo instante queda delimitada su obligación de indemnizar, sin que el acreedor pueda incluir a posteriori en su objeto otros daños que los previsibles. Esta regla se encuentra en el artículo 74 de la Convención de Viena y se vincula con el curso normal de los acontecimientos y el conocimiento que poseen las partes al tiempo del contrato y aquel que razonablemente debiesen poseer $^{70}$. El deudor cuando contrata asume el riesgo de indemnizar -en caso que el incumplimiento se produzca- los daños previsibles en ese momento, habida

70 Sobre el art. 74 de la Convención como regla de la razonable previsibilidad de las pérdidas y su vinculación con la idea del ámbito de protección del contrato, véase: PANTALEÓN (1998) pp. 579 y ss.; y STOLL (1998) pp. 552 y ss. 
cuenta el conocimiento que posee o debiese poseer, los que se identifican con aquellos daños que normalmente se producirían atendidas las circunstancias; el acreedor, por su parte, asume el riesgo de soportar aquellos daños imprevisibles y que, a su vez, se vinculan con circunstancias extraordinarias que exceden el curso normal de los acontecimientos. Si el acreedor desea, puede trasladar el riesgo de tales daños al deudor, pero debe hacerlo al momento del contrato, informando tales circunstancias extraordinarias, lo que evidentemente repercutirá en las condiciones del mismo, en especial, en el precio. Un deudor razonable trasladará al acreedor en forma de precio u otras condiciones contractuales los costos de administración de ese riesgo extraordinario.

c) La carga del acreedor de mitigar los daños mediante la adopción de medidas razonables. Si bien el acreedor tiene derecho a exigir la indemnización de los daños que hayan sido previsibles, al mismo tiempo, pesa sobre él la carga de mitigarlos mediante la adopción de medidas razonables en atención a las circunstancias del caso. La inobservancia de esta carga produce el efecto de rebajar de la indemnización aquellas pérdidas que eran razonablemente evitables y que el acreedor no evitó. Dicha rebaja se aplica sobre la indemnización ya definida de acuerdo a la regla de la previsibilidad. La carga de mitigación de las pérdidas se encuentra establecida por el artículo 77 de la Convención de Viena y se enmarca dentro del principio de la razonable gestión de los efectos del incumplimiento que la Convención impone al acreedor, de la que ya he hablado ${ }^{71}$.

En Viena el presupuesto de la responsabilidad por daños no se equipara exactamente con el mero incumplimiento que causa daños. En efecto, el principio de la controlabilidad del riesgo, contenido en el artículo 79, comprueba que si bien la regla es que el deudor responde por el solo hecho del incumplimiento, su responsabilidad no es absoluta, al reconocer un límite en la causa de exoneración que el citado precepto prevé. Expresado en otros términos, hay supuestos en los que, no obstante haber incumplimiento contractual, no hay responsabilidad del deudor por los daños causados. De la lectura positiva del artículo 79 aparecen los criterios concretos que explican la atribución de responsabilidad al deudor. El deudor no responde por los daños si acredita que la causa del incumplimiento fue un impedimento ajeno a su esfera de control, razonablemente imprevisible, inevitable e insuperable. En el precepto subyace la idea del razonable control que el deudor debe ejercer sobre el riesgo del incumplimiento. Aún más, cuando el deudor logra acreditar la causa de exoneración, el acreedor solo ve afectado su derecho a exigir la indemnización de daños, quedándole a salvo el ejercicio de cualesquiera de los otros remedios que la Convención pone a su disposición, como por ejemplo, la facultad resolutoria, la reducción del precio; o la reparación o la sustitución de las mercaderías no conformes al contrato. En el derecho de la compraventa internacional, la exoneración de responsabilidad solo interesa a

71 Para un estudio de la carga de mitigar las pérdidas en Viena, véase: ANGELICI (1992) pp. 274-286; BONELLI (1981) pp. 253 y ss, 297-308; ENDERLEIN (1991); SOLER (1998a); y SOLER (1998b) pp. 621-627. 
efectos de la indemnización de daños, no así respecto de los otros remedios distintos de aquella (párrafo 5 del artículo $79 \mathrm{CV}$ ).

Según el precepto citado, el deudor -sea el comprador o el vendedor- responde frente al acreedor cuando el incumplimiento de alguna de sus obligaciones tenga su causa en un impedimento u obstáculo inserto en su esfera de control, la que se dibuja recurriendo al principio de lo razonable. El límite de la esfera de control del deudor está representado por aquellos impedimentos imprevisibles al tiempo del contrato, inevitables e insuperables en sí mismos y en sus consecuencias; límite que coincide con la exoneración de responsabilidad. Cuando sobreviene uno de estos impedimentos, la obligación se integra por ciertos deberes de conducta cuya fuente es el propio estándar de lo razonable y que exigen al deudor superar el impedimento imprevisible o sus consecuencias, ejecutando la prestación inclusive a través de la entrega de un sustituto comercialmente razonable, y este lo será en la medida que sea igualmente idóneo para satisfacer el interés del acreedor afectado ${ }^{72}$.

En consecuencia, el artículo 79 cumple una doble función, explica el porqué el deudor responde, y fija el límite de su responsabilidad ${ }^{73}$.

\section{Un sistema de atribución de responsabilidad objetiva y estricta}

El principio de la razonable controlabilidad del riesgo, contenido en el artículo 79(1) CV., permite afirmar que en el derecho uniforme se instaura un sistema de atribución de responsabilidad objetiva y estricta ${ }^{74}$, que es la consecuencia de la realización del

\footnotetext{
72 Sobre la definición del contenido de la obligación contractual en Viena a partir de las reglas concretas de atribución de responsabilidad que se extraen del artículo 79 CV., véase: VIDAL (2005).

73 Sobre el alcance del artículo 79 y su carácter de norma de atribución de responsabilidad por incumplimiento, véase: VIDAL (2005b) pp. 55-88.

${ }^{74}$ En esta materia se sigue la terminología que emplea NiCHOLAS (1997) pp. 338 y ss. El autor distingue entre responsabilidad absoluta y estricta. En la primera, cualquier incumplimiento constituye un fundamento para una acción de indemnización de daños, sin que exista posibilidad de exoneración; en la segunda, la regla es la responsabilidad por daños por el incumplimiento, pero se admite la prueba de circunstancias exoneratorias de la misma (p. 340). Por su parte, Treitel distingue entre responsabilidad estricta y responsabilidad basada en la culpa, aludiendo con la primera a la que rige en las obligaciones de resultado y con la segunda a la que opera en las obligaciones de medios. Para el autor, en la responsabilidad estricta el mero hecho de que sobrevenga un evento, sin la culpa del deudor, que impida el cumplimiento no es suficiente para que sea aplicable la doctrina del discharge of contract. En cambio, en la responsabilidad basada en la culpa del deudor basta que el deudor haya ejecutado la actividad objeto de su obligación con razonable cuidado, y no es responsable porque el resultado perseguido no se alcance. En esta responsabilidad basta la prueba de haber empleado la diligencia debida. TREITEL (1994) par. 1-003-1-004. Pero el mismo autor TREITEL (1998) recurre a la referida distinción, esta vez en el sentido que interesa, distinguiendo entre responsabilidad por culpa y responsabilidad estricta (fault liability and strict liability); diferenciándose una de otra, en la posibilidad de exoneración por incumplimiento. En la primera, el deudor puede exonerarse de la obligación de indemnizar, si prueba que el incumplimiento se debió a una causa extraña [fuerza mayor]; en cambio, en la segunda, no cabe esa posibilidad, ni aun en los casos en que la falta de cumplimiento se debe a circunstancias totalmente ajenas al control del deudor. Dentro de los casos de responsabilidad estricta, menciona la obligación de pagar una suma de dinero y la de entregar cosas genéricas. Finalmente, ZWEIGERT y KÖTZ (1992) p. 689. Los autores emplean el término responsabilidad estricta en sede de responsabilidad extracontractual para aludir a aquella que prescinde de la culpa, es decir, a lo que nosotros denominamos responsabilidad objetiva.
} 
riesgo de que se produzca el incumplimiento, cuyo control ha sido asignado al deudor, sea por el contrato, sea por la Convención. El deudor es responsable porque el incumplimiento corresponde a la realización de un riesgo razonablemente controlable.

Es una responsabilidad objetiva porque la atribución de la misma prescinde de la culpa del deudor, o expresado de otro modo, el deudor responde sin consideración a si su incumplimiento se debió, o no, a su culpa; o a la inobservancia de la diligencia exigible $^{75}$. En el derecho uniforme hay un único estándar de conducta: el de lo razonable. $Y$ es una responsabilidad estricta porque admite la posibilidad de exoneración del deudor cuando el incumplimiento se ha debido a un impedimento fuera de su control $^{76}$. Sobre la posibilidad de exoneración en esta responsabilidad debemos precisar lo siguiente:

a) La regla general es que el deudor puede exonerarse de responsabilidad por el incumplimiento de cualquiera de sus obligaciones, si prueba que este se ha debido a un impedimento fuera de su control ${ }^{77}$. Sin embargo, la Convención define la causa de exoneración en términos tan estrictos que consagra un sistema de exoneración limitada a hipótesis de incumplimiento muy excepcionales. Por decirlo de alguna manera, se presume la razonable controlabilidad del riesgo de incumplimiento, de modo que si este se realiza, atribuye inmediatamente responsabilidad al deudor.

b) A lo anterior se suma la circunstancia que si bien cabe la exoneración, la Convención prevé una regla de atribución de responsabilidad absoluta -sin posibilidad de exoneración- cuando el impedimento se ubica en la esfera típica de control del deudor. Es decir, si el citado impedimento coincide con cualquiera de los aspectos que integran la propia empresa u organización del deudor, él no puede alegar su exoneración de responsabilidad, sino que solo le queda indemnizar los daños conforme las reglas generales (artículos 74 a 77 CV). Dentro de esta esfera la responsabilidad que rige es de carácter absoluto ${ }^{78}$.

De lo afirmado hasta aquí se infiere que el principio de la controlabilidad del riesgo se desdobla en dos aspectos: el primero, la esfera típica de control del deudor y, el segundo, la controlabilidad del impedimento más allá de esa esfera en tanto aquel era razonablemente previsible al momento de la celebración del contrato; o, no siéndolo, este, o sus consecuencias, eran razonablemente evitables, o superables posteriormente. Y

\footnotetext{
75 Por todos: MORALES (1997) p. 19; y STOLL (1998) par. 1.1.

76 Cfr. con. Ferrarini (1981). El autor nos habla de que en la Convención se consagra un sistema de responsabilidad contractual objetivo no absoluto, sino temperado por la posibilidad de exoneración del deudor incumplidor.

77 LOOKOFSKY (1996a) pp. 78-79; y LOOKOFSKY (1996b) p. 102.

78 Cfr. STOLL (1998) par. 27. El autor afirma que en el art. 79 CV se aplica la regla de que el deudor responde dentro de su esfera típica de control, sin ninguna posibilidad de exoneración. En un mismo sentido FERRARINI (1981); SCHLECHTRIEM (1986) p. 104. También, aunque indirectamente: Morales (1997) pp. 19-21.
} 
estos dos aspectos permiten dibujar dos áreas bien definidas de localización de la causa del incumplimiento ${ }^{79}$.

La primera, correspondiente a la esfera típica de control del deudor, y la segunda, aquella que se extiende más allá de dicha esfera ${ }^{80}$. La esfera típica de control del deudor representa su empresa u organización -su ámbito de influencia- y dentro de ella, como se ha expresado, le afecta un régimen de atribución de responsabilidad absoluta, en el que no hay lugar a exoneración alguna. La esfera típica de control del deudor se define objetivamente para cada operador y encierra todas las medidas de organización y de control apropiado, que razonablemente puede esperarse que el deudor adopte; y que se estiman necesarias para asegurar la adecuada preparación de la prestación prometida y, en definitiva, el cumplimiento fiel y oportuno del contrato ${ }^{81}$. Al deudor se le asigna el riesgo de todo lo que afecte al proceso de preparación y ejecución de la prestación porque de él depende la adopción de todas aquellas medidas que permitan asegurar dicho proceso y, consecuentemente, evitar que el incumplimiento se produzca. La decisión de cómo y en qué condiciones se cumple la obligación corresponde al deudor y lo hace a su propio riesgo, respondiendo siempre de cualquier incumplimiento, que tenga su origen en la omisión de aquello que una persona razonable en su misma posición y circunstancias hubiese hecho. La CV presupone que el deudor debe evitar y superar todas aquellas circunstancias o sucesos relacionados con la preparación y ejecución de la prestación y que puedan perturbar el cumplimiento fiel y oportuno del contrato. La

\footnotetext{
79 Así lo reconoce STOLL (1998) par. 27. El autor estudia separadamente la controlabilidad del riesgo fuera de la esfera típica de control del deudor [párrafos. 20-25], de la responsabilidad de este dentro de aquélla [párrafos. 27-32]. Del mismo modo Morales Morales (1997) pp. 19-21. El autor afirma que la CV. atribuye responsabilidad al deudor dentro de su esfera típica de control y fuera de la misma. En esta área el deudor responde por los impedimentos razonablemente previsibles, puesto que al poderlos prever, si contrata sin excluirlos, se entiende que los asume [1]; y por aquellos impedimentos cuyo riesgo no ha quedado atribuido al momento del contrato, pero que posteriormente la ejecución del contrato le atribuye [2]. El autor afirma que esta última es una regla de ejecución de la prestación establecida por la CV. que se concreta según el criterio de lo razonable. En esta misma línea: MASKOW y ENDERLEIN (1992) pp. 322324; y SCHLECHTRIEM (1986) p. 101.

$80 \mathrm{Si}$ se tuviese que explicar gráficamente las reglas de atribución de responsabilidad y de exoneración contenidas en el art. 79, (1) CV., diríamos que el ámbito de atribución de responsabilidad y de su exoneración, se dibuja a través de círculos concéntricos. El núcleo contiene la regla de atribución de responsabilidad de la esfera típica de control. Como la responsabilidad del deudor va más allá de esta esfera típica, nos encontramos con un círculo inmediatamente posterior que encierra un área de atribución de responsabilidad, ahora estricta, con posibilidad de exoneración. Estos dos círculos delimitan el ámbito de atribución de responsabilidad del deudor, de modo que todo lo que exceda del mismo supone, a pesar del incumplimiento, su exoneración. Finalmente, se llega al tercer círculo, en el que el deudor está exonerado de responsabilidad, no obstante el daño que efectivamente haya sufrido el acreedor a causa de la insatisfacción de su interés negocial. Cfr. Pichonnaz (1997) par. 1708.

${ }^{81}$ En la doctrina que comenta el art. 79 CV., Stoll emplea esta expresión para referirse al área dentro de la cual el deudor responde sin posibilidad de exoneración. STOLL (1998) pars. 28-29. Salvador Coderch, siguiendo a Stoll, habla de la "esfera de influencia del deudor típicamente integrada". SALVAdOR (1998) pp. 642 y 648. En cambio, otros autores sin emplear la expresión identifican ciertos supuestos de impedimentos en que no cabe la exoneración a favor del deudor. Así Pichonnaz se refiere a "hipótesis típicas dentro del ámbito de influencia del deudor”. PiCHONNAZ (1997) pars. 1682; 1688, 1691-1692. Por su parte Schlechtriem alude a la "garantía del deudor sobre su capacidad de cumplir". SCHLECHTRIEM (1986) pp. 101-103.
} 
esfera típica de control del deudor la integran elementos subjetivos y objetivos ${ }^{82}$. Los primeros encierran tanto el comportamiento y circunstancias personales del propio deudor como de todo el personal sujeto a su organización y supervisión que intervenga o colabore directamente en la prestación. Los segundos, en cambio, concierne a todos aquellos bienes, materiales e inmateriales, que condicionan el cumplimiento del contrato. Todo incumplimiento que tenga su origen en un suceso referido a alguno de los elementos de esta esfera que impida u obstaculice el cumplimiento atribuye responsabilidad absoluta al deudor (primera regla de atribución de responsabilidad).

La segunda área se extiende más allá de la esfera típica de control y comprende aquellos impedimentos que pese a estar fuera de dicha esfera, son razonablemente controlables por el deudor conforme las propias reglas del párrafo (1) del artículo 79, y estas reglas son ${ }^{83}$ :

i) La razonable previsibilidad del impedimento al momento del contrato y que despliega su eficacia independientemente de su real posibilidad de control. Su fundamento está en la circunstancia de que el deudor -pese a que una persona razonable de su condición y en sus circunstancias se habría representado el impedimento- no protestó excluyéndolo del contrato. Al no decir nada el deudor, se entiende que este, como persona razonable que es, adoptará las medidas que sean convenientes para superar y evitar el impedimento, como sus consecuencias, o que consideró en el cálculo previo a la celebración del contrato los eventuales costos de su realización ${ }^{84}$. De forma que si el impedimento tiene lugar, el deudor responde como si este se hubiese asentado dentro de su esfera típica de control.

ii) La razonable evitabilidad o superabilidad del impedimento imprevisible o de sus consecuencias. La atribución de responsabilidad se apoya en la posibilidad de un control efectivo del riesgo por una persona razonable ubicada en la posición del deudor afectado por el impedimento imprevisible. Se trata de una regla de ejecución de la prestación que ordena su integración e impone al deudor una actuación y unos costos que exceden de los previstos o previsibles al tiempo de contratar, pero siempre sujeto al límite de lo razonable. Esta regla es la que puede llevar al deudor a cumplir con un sustituto comercialmente razonable, idóneo para la satisfacción del interés del acreedor, lo que se traduce en que pueda

82 Así se recoge: PANTALEÓn (1993) p. 1069. En una interpretación objetiva del art. 1105 del Código Civil español, inspirada en el principio del razonable control del riesgo del art. $79 \mathrm{CV}$, afirma categóricamente que el criterio de "esfera de control del deudor" engloba los subcriterios de "hecho del deudor" y "hecho de los auxiliares en el cumplimiento" y agrega que, con base a este criterio (esfera de control), el deudor no solo responde de sus hechos propios, o de sus dependientes, o auxiliares, en el cumplimiento, sino también, como regla, del estado de los elementos materiales (maquinarias, utensilios, medios de transporte) utilizados en su actividad empresarial o profesional y, en definitiva, de la correcta organización y buen funcionamiento de la misma.

83 Reconociendo estas dos reglas de atribución de responsabilidad: STOLL (1998) par. 9; PICHONNAZ (1997) pars. 1707-1708.

${ }^{84}$ Cfr. TAllon (1987). El autor se refiere a la idea de que si el deudor contrata sin protestar acerca del impedimento previsible, se entiende que asume el riesgo de que el cumplimiento pueda verse afectado por el mismo. 
cumplir alterando la prestación comprometida, sea en relación a su objeto, sea en relación a las modalidades de ejecución. La identidad de la prestación cede ante la necesidad de la satisfacción del interés del acreedor ${ }^{85}$.

Si el impedimento cae dentro del ámbito de cualquiera de estas reglas, el deudor responde porque era razonable que controlara el riesgo de incumplimiento, pero no lo hace y ello obsta el cumplimiento fiel y oportuno de la obligación concernida.

A lo anterior se suma un área de atribución de responsabilidad intermedia situada entre la esfera típica de control del deudor, regida por una responsabilidad absoluta, y aquella que está más allá de dicha esfera, en la que el deudor puede exonerarse bajo ciertas condiciones. El artículo 79 (2) permite delinear esta área y ella contiene la llamada regla de los terceros encargados, cuyo supuesto es que cualquiera de las partes encarga a un tercero una parte de su prestación y este incumple causando el incumplimiento del deudor de la compraventa internacional que hace el encargo ${ }^{86}$. Se atenúa la responsabilidad del deudor dentro de su esfera de control; y al mismo tiempo se prevé un régimen de exoneración más exigente respecto del instaurado por el artículo 79 (1), segunda parte ${ }^{87}$. Sobre el particular, conviene hacer dos precisiones. En primer lugar, la responsabilidad del deudor no se

${ }^{85} \mathrm{La}$ institución del sustituto comercialmente razonable está establecida expresamente por el UCC. norteamericano en su sección 2-614, y se vincula con supuestos de impracticabilidad comercial del cumplimiento (sección 2-615 UCC). El deudor cumple con una prestación que difiere de lo acordado por las partes, pero que igualmente es idónea para satisfacer el interés del acreedor, evitando, de este modo, el breach of contract. El deudor queda liberado de la obligación de indemnizar pese a la alteración de la prestación. Para un estudio del sustituto comercialmente razonable en el derecho norteamericano, véase: CALAMARI y PERILLO (1987) pp. 266 y ss. Reconociendo el cumplimiento a través de un sustituto comercialmente razonable en Viena, se encuentran: AUDIT (1990) par. 182: "El hecho de superar el impedimento puede llevar a una parte a ejecutar su obligación en condiciones ligeramente diferentes a las previstas. Esto debe ser admitido, sujeto a la condición de que la ejecución realizada sea razonablemente satisfactoria en el plano comercial"; MASKOW y ENDERLEIN (1992) par. 13.6. Los autores opinan que, en algunos casos, el problema de la superación del impedimento, o sus consecuencias, puede resolverse aceptando que el derecho a exigir el cumplimiento persigue la entrega de un sustituto comercialmente razonable. PICHONNAZ (1997) pars. 1749 y 1757 y ss. "El test de insuperabilidad impone al deudor estar preparado para proveer una prestación aun ligeramente modificada"; SALVADOR (1998) p. 647. El autor limita la noción de cumplimiento sustituto a las modalidades del cumplimiento, y expresa que: "Los impedimentos insuperables, pero que solo afectan a las modalidades de la prestación (medio de transporte o de pago, embalaje) tampoco tienen carácter exoneratorio, si existe una alternativa comercialmente razonable de cumplir y aunque esta suponga modificar la modalidad de que se trata"; y STOLL (1998) par. 24: "La evitabilidad dentro del contexto del art. 79, significa facultad de evitar una perturbación real al incumplimiento causado por un impedimento específico, siendo posible evitar dicha perturbación mediante el cumplimiento con un sustituto comercialmente razonable en lugar de la entrega de las mercaderías conformes al contrato, que no es posible por efecto del impedimento".

${ }^{86}$ Véase: VIDAL (2006).

${ }^{87}$ Reconociendo la mayor severidad del art. 79 (2), Adame Goddard expresa: "la exigencia de que el cumplimiento del tercero sea, para la parte obligada, un impedimento ajeno a su voluntad, imprevisible, inevitable e insuperable, hace recaer en esta una responsabilidad grande por el incumplimiento del tercero, ya que será responsable si encargó la ejecución del contrato a un tercero que una persona razonable habría previsto que no cumpliría, quizá porque no contaba con la capacidad financiera o técnica adecuada; o será responsable si el incumplimiento del tercero podía evitarse dándole apoyo financiero oportuno, o si podía superarse encargando con oportunidad la ejecución del contrato a otro que fuera capaz", ADAME (1994) p. 219. En el mismo sentido: KRITZER (1996) p. 646; LOOKOFSKY (1993) pp. 129-132; y NiCHOLAS (1989) p. 237. 
atenúa en el sentido que quede exonerado con la sola prueba que las consecuencias del incumplimiento del tercero encargado eran razonablemente insuperables según el artículo 79 (1); se requiere, además, la prueba de la exoneración del tercero encargado, esto es, que su incumplimiento esté justificado por un impedimento fuera de su control según el artículo 79 (1). En segundo lugar, la mayor exigencia del test de exoneración no se traduce en la aplicación de criterios distintos de los del párrafo (1), son los mismos, pero ahora aplicados, tanto al deudor principal, como al tercero encargado. La Convención protege los intereses del deudor principal, autorizando su exoneración, pero como contrapartida, su protección queda sujeta a requisitos más estrictos que los generales del artículo 79 (1). $\mathrm{Y}$ esta mayor exigencia viene justificada por la asignación al deudor del riesgo inherente al encargo a un tercero del cumplimiento del contrato. Los Tribunales han resuelto recientemente que la regla en el caso de los terceros encargados es la responsabilidad del deudor principal, salvo que pruebe las condiciones del artículo 79 (2) referidas al deudor principal $y$ al tercero incumplidor ${ }^{88}$.

La definición de la causa de exoneración -límite de la atribución de responsabilidad- supone la inaplicabilidad, para el caso concreto, de las reglas descritas de atribución, incluida la de la esfera típica de control. El límite de la responsabilidad, con base en la razonable controlabilidad del riesgo, se halla en la regla de atribución de la letra b) y que se expresa en la razonable insuperabilidad del impedimento o sus consecuencias ${ }^{89}$.

88 Véase Tribunale d'Apello di Lugano (2004).

89 Así se recoge de Hans Stoll: "La idea básica de cómo debe interpretarse el art. 79 es que el cumplimiento del contrato ha sido impedido por algo fuera de la esfera de control del deudor"; y agrega que ello sucederá cuando la falta de cumplimiento es (a) debido a un impedimento que está (b) fuera de su control (c) inevitable, en el sentido que no podría razonablemente haberse esperado que el deudor lo tomase en cuenta en el tiempo de la celebración del contrato o hubiese evitado o superado el impedimento o sus consecuencias. STOLL (1998) par. 16.

${ }^{90}$ En la versión española de la CV, el art. 79 (1) establece como causa de exoneración "el impedimento ajeno a la voluntad del deudor", que corresponde a la traducción literal de la expresión empleada en la versión francesa: "empêchement indepéndant de sa volontê". En cambio, el texto inglés emplea la expresión "impediment beyond of his control" [impedimento fuera de su control]. Del mismo modo, la versión no oficial en alemán, prescindiendo de la francesa y española, habla de "Hinderungsgrund ausserhalb ihres Einflussbereichs", cuyo significado en español es: obstáculo fuera del ámbito de su influencia. Sin lugar a duda, esta expresión es extraída de la versión en inglés del art. 79 (1) CV. Si se comparan las versiones española, francesa y la inglesa, evidentemente la terminología de esta [impediment beyond his control] resulta más conforme con la intención de los redactores de la Convención en orden a objetivar los motivos de exoneración; siendo, por ende, más adecuada al sistema de atribución de responsabilidad de la Convención basado en la razonable controlabilidad del riesgo. Las primeras versiones señaladas no son una expresión de este carácter objetivo de la responsabilidad del deudor, como sí lo es la versión en inglés. Por esta razón, y considerando que el Derecho internacional autoriza preferir una versión idiomática por otra más adecuada, en el caso del art. 79 (1) se opta por la versión idiomática inglesa, prescindiendo de la española y la francesa. El art. 33 No 4, de la Convención de las Naciones Unidas sobre Derecho de los Tratados, autoriza esta opción, cuando de la comparación entre distintos textos auténticos se descubre una diferencia, debiendo adoptarse el significado que mejor reconcilie los textos, habida cuenta el objeto y la finalidad del tratado. Sobre el particular, no debe olvidarse que el idioma empleado en la discusión, aprobación y redacción de las disposiciones de la Convención es el inglés y por ello el texto definitivo es más acorde con la verdadera intención de los redactores. La traducción de las versiones en otros idiomas se hace a partir del texto en inglés, y si hay discordancia entre una versión y la otra, deberá preferirse el texto en idioma inglés por sobre aquel que intente adaptar la terminología del Derecho Uniforme a una más familiarizada a un determinado sistema jurídico vinculado con el idioma relevante. Para un mayor estudio, véase: VIDAL (2005b). 
En efecto, el deudor se exonera en la medida que el impedimento ubicado fuera de la esfera típica de control fue imprevisible y sus consecuencias eran razonablemente insuperables. En último término, la causa de exoneración es el impedimento ajeno a la esfera de control del deudor ${ }^{90}$ y la exoneración está definida por la razonable insuperabilidad de las consecuencias del impedimento imprevisible ${ }^{91}$.

Conviene ilustrar el modo cómo actúa el principio del razonable control del riesgo como fundamento de la responsabilidad por daños en la Convención.

En un contrato para la venta y entrega de muebles de oficina de propia fabricación del vendedor, este no cumple con su obligación a causa de la completa destrucción de su fábrica como resultado de un incendio. En este caso, el impedimento del cumplimiento es el incendio que destruyó la fábrica y sus consecuencias son que el deudor no pudo realizar su prestación entregando las mercaderías porque ellas fueron dañadas por el fuego (Incumplimiento contractual) ${ }^{92}$. Enfrentado al incumplimiento, el comprador reacciona resolviendo el contrato ${ }^{93}$ y demanda la indemnización de daños. Acorde lo dispuesto en el artículo $74 \mathrm{CV}$, el vendedor responde por los daños por el mero hecho del incumplimiento. Queda por explicar la atribución de responsabilidad. Como se ha expresado, ella puede estar determinada, o por la primera regla, la esfera típica de control del deudor, o por aquellas aplicables más allá de la misma. Para definir qué regla de atribución es aplicable al caso, debe averiguarse cuál fue la causa del incendio. Así, por ejemplo, ella se ubicará dentro de la esfera típica de control del vendedor, si el siniestro se debió a una falla en las instalaciones eléctricas o de gas de la fábrica, sin importar la causa de la falla (fabricación o mantenimiento). Si es así, nada habrá que discutir sobre la exoneración del deudor, él responde en todo caso $^{94}$. Sin embargo, puede suceder que el incendio se haya debido a un hecho externo, ajeno a la esfera típica del deudor; por ejemplo, el incendio del edificio colindante, o a una explosión de un vehículo, o a la expansión de un incendio forestal. La sola constatación de que la causa del incendio fue un hecho externo, ajeno a la esfera típica del deudor, no ofrece una respuesta definitiva sobre la exoneración del deudor, dado que él igualmente podría ser responsable. Debe aplicarse el test de la razonable controlabilidad del riesgo del artículo 79 (1), segunda parte. Acorde con la norma, el deudor responde cuando cabía razonablemente esperar que tuviese en cuenta el riesgo de ese concreto impedimento al momento de la celebración del contrato. Por ejemplo, el establecimiento donde

91 Cfr. con Pichonnaz (1997) par. 1771.

92 Cfr. con Ejemplos 65 A (mercaderías especificas) y 65 B (mercaderías fungibles), UNCITRAL, Secretariat Commentary CISG, Art. 65, par. 9, p. 55. Se propone un caso de compraventa de máquinas que resultan destruidas por un incendio antes de la transmisión del riesgo al comprador. En ambos ejemplos se da por supuesto que el incendio constituye un impedimento fuera del control del deudor.

93 Partiendo de la base de que concurre el presupuesto de hecho resolutorio (Véase: art. $49 \mathrm{CV}$ ).

${ }^{94}$ En este sentido: MASKOW y ENDERLEIN (1992) par. 3.6. Los autores ofrecen el ejemplo del incendio que ha sido a consecuencia de la violación de los más elementales requerimientos de prevención de incendios, por lo que debe concluirse que ese resultado estaba dentro de su esfera de control. 
funciona la fábrica colinda con una gasolinera, o con una empresa de químicos inflamables, o bien está emplazado en una zona rodeada de bosques de pino insigne que habitualmente se incendian en esa época del año. Aquí, la atribución de responsabilidad tiene su fundamento en la razonable previsibilidad del impedimento. Pero aun en el supuesto que el impedimento haya sido razonablemente imprevisible, el deudor responderá igualmente si el impedimento o sus consecuencias eran razonablemente evitables o superables, como por ejemplo, a través de la compra de mercaderías de reemplazo o encargando la fabricación de las mismas a un tercero. O sea, si la respuesta es afirmativa, igualmente responderá y no cabría la exoneración; o ella se extenderá solo por el tiempo en que duró la razonable insuperabilidad de las consecuencias del impedimento.

Esta ilustración muestra la rigurosidad del régimen de atribución de responsabilidad en Viena.

\section{Distinción entre la responsabilidad por daños y los otros derechos y acciones}

Como se anunció, en materia de efectos del incumplimiento de cualquiera de las obligaciones del deudor, la Convención distingue la responsabilidad contractual -o el remedio de la indemnización de daños- de los restantes remedios (derechos y acciones) conferidos al acreedor afectado por el incumplimiento, con la finalidad de que supere la situación de insatisfacción negocial originada por el mismo. Esta distinción se aprecia nítidamente desde una doble perspectiva: En primer lugar, desde los remedios del acreedor por el incumplimiento de cualquiera de las obligaciones contractuales (artículos 45 y 61, según el caso). El párrafo (1) de ambas disposiciones fija el supuesto de hecho que desencadena el funcionamiento del sistema unitario de remedios: el incumplimiento de cualquiera de las obligaciones que le incumba al deudor. En segundo lugar, desde la perspectiva de la atribución de responsabilidad, el artículo 79 (5) de la Convención prescribe que el efecto de la exoneración incide únicamente en el remedio de la indemnización de daños (responsabilidad en sentido estricto), salvando el ejercicio de los otros derechos y acciones de las partes ${ }^{95}$.

En efecto, el artículo 79 (5) limita el alcance de la exoneración a la indemnización, disponiendo que las partes conservan cualesquiera otros derechos y acciones que conforme la CV le incumban ${ }^{96}$. En otros términos, la exoneración solo excluye la atribución de responsabilidad por daños y como el supuesto de aquella es igualmente el del "incumplimiento contractual" (artículos 45 (1) a); 61(1) a), el acreedor conserva los remedios restantes ${ }^{97}$.

95 Cfr. con STOLl (1998) par. 39; y par. 52.

96 En este sentido: LOOKOFSKY (1996) pp. 78-79; NiCHOlAS (1979) p. 241; UnCITRAL, Secretariat Commentary CISG, Art. 65, pars. 2 y 8. STOLL (1998) par. 39; y par. 52; y TALLON (1987) par. 3.1.2.

97 En el caso del acreedor agraviado con el incumplimiento: los remedios de la resolución por incumplimiento, reducción del precio e intereses por el retraso en el cumplimiento de pagar el precio o cualquier otra cantidad adeudada. Con relación al cumplimiento específico en cualquiera de sus modalidades (ejecución in natura, reparación o sustitución de las mercaderías) obviamente la regla no puede ser así de 
La distinción entre la responsabilidad por daños y los otros remedios por el incumplimiento se explica sobradamente porque: a) el impedimento exoneratorio del artículo 79 no extingue necesariamente la obligación y ello justifica la subsistencia de los remedios de cumplimiento específico, en cualquiera de sus modalidades (cumplimiento forzado, sustitución y reparación de las mercaderías defectuosas); de la reducción del precio; y el ejercicio de la facultad resolutoria ${ }^{98}$; y b) en la Convención el supuesto de hecho de la exoneración sigue siendo el incumplimiento contractual, con el añadido que su causa ha sido un impedimento fuera del control del deudor. El correlativo de que la obligación contractual subsista, a pesar de la exoneración de responsabilidad, según el artículo 79 (5), es que el deudor amparado por el motivo de exoneración, al igual que el acreedor afectado, conserva todos los derechos y acciones que le reconoce el contrato y la Convención, dentro de los que se halla el derecho a cumplir con su obligación, o subsanar su incumplimiento, de conformidad a lo dispuesto en los artículos 47 y $48 \mathrm{CV}$.

De esta manera, se observa con claridad cómo en el sistema de remedios por incumplimiento de la Convención conviven el efecto exoneratorio y la posibilidad de ejercicio, dentro de los límites que ella misma consulta, de los derechos y acciones de las partes distintos a la indemnización de daños ${ }^{99}$.

En el caso del incumplimiento del vendedor amparado por una causa de exoneración deben considerarse los remedios de que dispone el comprador, distintos de la indemnización de daños. El artículo $45 \mathrm{CV}$ consulta el catálogo general de remedios de que dispone el comprador para el caso de que el vendedor no cumpla cualquiera de las obligaciones que le incumben según el contrato y la Convención. Estos remedios son los regulados por los artículos 46 a 52 y corresponden a los siguientes: A) El derecho a exigir el cumplimiento específico (ex artículo 46 $\mathrm{CV})$, que procede cualquiera sea el incumplimiento. El ejercicio de este derecho está sujeto a que el vendedor no ejerza un derecho incompatible con el mismo

absoluta, dado que si la causa de exoneración incide en la exigibilidad de la obligación, al menos debe reconocerse al deudor, demandado de cumplimiento específico, el tiempo necesario para superar las consecuencias del impedimento. En otras palabras, la disponibilidad de este remedio también podría verse afectada, llegando incluso a la privación del mismo, si las consecuencias del impedimento son insuperables definitivamente. Cfr. Huber (1998) p. 378. El autor, apoyándose únicamente en la norma del art. 46 (1), expresa: "If the failure to perform is caused by an impediment for which the seller can claim exemption under Article 79, the buyer has not right to require performance. Although Article 79 does not lay down an express rule to that effect and merely excludes liability in damages, the exclusion if the right to require performance follows from the spirit of Article 46(1). It would be inconsistent to allow a buyer to require perfomance where performance is prevented by an impediment which, by virtue of Article 79, the seller is not required to overcome". Reconociendo el límite del art. 79, pero matizando en el sentido que la procedencia del remedio del cumplimiento específico dependerá de las circunstancias del caso, se encuentra: STOLL (1998) pp. 622-623.

98 En caso de que la obligación incumplida no pudiese ser ejecutada, igualmente, la relación contractual se mantiene, salvo que el acreedor haga uso de la facultad resolutoria. En el supuesto se incluye los supuestos de extinción de la obligación y aquellos en los que, a pesar de su subsistencia, el ejercicio del remedio del cumplimiento específico no es razonable (insuperabilidad permanente de las consecuencias del impedimento).

99 Sobre el alcance de la disposición del artículo 79 (5) CV, véase: VIDAL (2005b). 
(resolución ex artículo 49 o reducción del precio ex artículo 50) y que, acorde el artículo $28 \mathrm{CV}$, el tribunal lo declare ${ }^{100}$. Si hay falta de conformidad conforme el artículo $35 \mathrm{CV}^{101}$, el cumplimiento específico adopta dos modalidades: la reparación de las mercaderías en la medida que ella sea razonable según las circunstancias y la sustitución de las mismas, si la falta de conformidad constituye incumplimiento esencial (artículo 46 (2) y (3) CV) ${ }^{102}$. B) Resolución total ex artículo 49 $\mathrm{CV}$. Por regla general la procedencia de este remedio exige que el incumplimiento sea esencial según el artículo $25 \mathrm{CV}^{103}$. Sin embargo, se contemplan supuestos en los que no tiene relevancia la importancia del incumplimiento, sí la concurrencia de otros requisitos de una mayor objetividad ${ }^{104}$. C) La reducción del precio de acuerdo a la fórmula contemplada en el artículo $50 \mathrm{CV}$.

\section{CONCLUSIONES}

1.- En la Convención de Viena se recoge un concepto amplio y objetivo de incumplimiento entendido como cualquiera desviación del programa de prestación objeto del contrato. El deudor garantiza la satisfacción del acreedor comprometiendo toda

\footnotetext{
${ }^{100}$ Me refiero a la limitación del art. 28 de la Convención, precepto cuyo destinatario es el tribunal que conoce de la petición de cumplimiento específico. Esta disposición envuelve una importante limitación a la procedencia del remedio del cumplimiento específico, tanto es así que pese a que concurran todos los requisitos para su ejercicio, el juez del foro, recurriendo a su propio derecho sustantivo, podría rechazar la pretensión por no estar obligado a concederla en contratos de compraventa similares a los que rige la Convención. En la doctrina, Will sostiene que el comprador que ejercite su acción en ciertas partes del mundo, especialmente en aquellos Estados pertenecientes a la familia del Common Law, tendrá una carga y un riesgo adicionales de convencer a los tribunales que bajo su derecho del foro procede el remedio del cumplimiento específico. Este razonamiento acarrea un grado importante de incertidumbre. Y agrega que esta incertidumbre aumenta cuando los tribunales concluyen que ellos no pueden conceder ese remedio. WILL (1987) p. 340

101 Según el citado art. 35 el vendedor debe entregar mercaderías cuya cantidad, calidad y tipo corresponda a lo que estipula el contrato; y envasadas y embaladas en la forma convenida por las partes o lo prescrito por la Convención. Puede decirse que la conformidad consiste en su adecuación material de las mercaderías con las que el vendedor pretende cumplir con las previsiones del contrato y de la propia Convención, que se refiere a su cantidad, calidad, tipo, envase y embalaje [art. 35 (1) CV]. SCHWENZER (1998) pp. 276-278

102 Para el ejercicio de cualquiera de estos remedios, según el art. 46 (2) y (3) el comprador debe comunicarlo al vendedor al momento de denunciar la falta de conformidad de las mercaderías conforme el art. 39 o bien dentro de un plazo razonable contado desde este último momento.

${ }^{103}$ La Convención define el incumplimiento esencial en su art. 25 exigiendo que este cause un detrimento que prive sustancialmente al acreedor de aquello a lo que tenía derecho esperar en virtud del contrato siempre que ello hubiese sido razonablemente previsible al momento del contrato por el deudor incumplidor. En la doctrina, Schlechtriem explica que de la historia del establecimiento del precepto aparece claramente que cuando exige que el incumplimiento cause a la otra parte un perjuicio que la prive sustancialmente de lo que tenía derecho a esperar en virtud del contrato no está refiriéndose a la extensión de los daños contractuales, sino a la importancia del interés contractual del acreedor. SCHLECHTRIEM (1998) p. 177.

$104 \mathrm{Si}$ no se ha producido la entrega y el comprador confiere un plazo adicional de duración razonable al vendedor para que cumpla y no lo hace o bien declara que no cumplirá, el comprador dispone directamente de la facultad resolutoria (art. 49 (1) b).
} 
aquella actividad que sea razonable esperar de él, quedando incluso obligado a evitar y superar los impedimentos imprevisibles al tiempo del contrato y sus consecuencias.

2.- Frente al incumplimiento, el acreedor dispone de una serie de remedios entre los cuales puede optar libremente. Todos estos remedios se articulan a partir del incumplimiento. Por ello se habla de un sistema unitario. En este sistema cada remedio tiene su propio supuesto de hecho. La opción pertenece al acreedor, de guisa que si concurre el supuesto de hecho del remedio puede libremente ejercitar el remedio que mejor convenga a su interés afectado por el incumplimiento.

3.- Empero, la Convención le impone una gestión razonable de los efectos del incumplimiento que se manifiesta en la necesidad de observar cargas de comunicación y de conducta material, en términos que si no lo hace, bien se le priva del derecho a invocar el incumplimiento, bien se limitan los efectos que el incumplimiento produce, sea privándole de un remedio particular, sea rebajándole la indemnización de daños.

4.- La Convención establece una responsabilidad objetiva y estricta. El deudor responde al margen de su culpa, por el solo hecho del incumplimiento, a menos que pruebe que este se debió a un impedimento ajeno a su esfera de control en los términos del artículo 79 (1) CV.

5.- La responsabilidad se extiende a todos los daños que sean una consecuencia del incumplimiento razonablemente previsible al momento del contrato, con exclusión de aquellos daños que el acreedor habría podido prevenir o evitar de haber observado una conducta razonable. Sobre el acreedor pesa la carga de mitigar las pérdidas mediante la adopción de medidas razonables.

6.- La exoneración de responsabilidad solo incide directamente en la indemnización de daños y en algunos casos en el ejercicio de la pretensión de cumplimiento específico. El acreedor a pesar de la exoneración de responsabilidad tiene a salvo el ejercicio de los restantes remedios y el deudor también queda en posición de ejercitar los derechos que la Convención le reconoce, como el ofrecer al acreedor subsanar o corregir su incumplimiento.

7.- En la Convención se distingue nítidamente la responsabilidad civil que se identifica con la indemnización de daños y los restantes remedios como son la pretensión de cumplimiento, incluidas sus modalidades de reparación y sustitución de las mercaderías no conformes, la reducción del precio y la resolución del contrato.

\section{BIBLIOGRAFÍA CITADA}

AlbieZ, Klaus (2002a): "Un nuevo derecho de las obligaciones. La reforma 2002 del BGB", Anuario de Derecho Civil, vol. LV: pp. 1133-1228.

AlbieZ, Klaus (2002b): "La modernización del derecho de las obligaciones en Alemania: un paso hacia la europeización del derecho privado", Revista de Derecho Privado: pp. 187-206.

AngeliCI, Carlo (1992): “Art. 77”, en: BIANCA, Massimo (edit.), Convenzione di Vienna sui Contratti di Vendita Internazionale di Beni Mobili (Milano, Cedam Editore) pp. 274-286. 
AudiT, Bernard (1990): La vente Internationales de Marchandises, Convention des Nations-Unies du 11 avril 1980 (Paris, Editorial L.G.D.J.) 240 pp.

BARRERA, Jorge (1987): “Art. 85-88”, en: BiANCA y BONELL (edit.), Commentary on the International Sales Law, The Vienna Sales Convention (Milan, Editorial Giuffré) pp. 613-632.

Berlingieri, Francesco (1981): "Lo standard del "Reasonable Man", La Vendita Internazionale. La Convenzione di Vienna dell'11 Aprile 1980”, Quaderni di Giurisprudenza Comerciale vol. 39: pp. 327-340.

BeTTI, Emilio (1953): Teoría general del negocio jurídico (Traducc. Martín PÉREZ, Madrid, Editorial Revista de Derecho Privado) 465 pp.

Bonelli, Franco (1981): “La responsabilità per danni. La Convenzione di Vienna dell' 11 aprile 1980", Quaderni di Giurisprudenza Commerciale vol. 39: pp. 251-299.

Bonelli, Franco (1992): "Artículos 74 a 77 ”, en: BiancA, Massimo (edit.), Convenzione di Vienna sui Contratti di Vendita Internazionale di Beni Mobili (Milano, Cedam Editore) pp. 297-308.

CABAnillas SÁnCHEZ, Antonio (1988): Las cargas del acreedor en el Derecho Civil y en el Derecho Mercantil (Madrid, Editorial Montecorvo) 400 pp.

Calamari y Perillo (1987): Contracts (St. Paul Minn., West Publishing Co) 1.049 pp.

CAmpBell, Henry et al. (1990): Black's Law Dictionary (St. Paul, Minn, Editorial West Group)

CASSONI, Giussepe (1982): "La compravendita nelle convenzioni en el diritto internazionale privato", Rivista di Diritto Internazionale Privato e Processuale vol. 18: pp. 429-483.

DíEZ-PICAZO, Luis (1964): "El contenido de la relación obligatoria", Anuario de Derecho Civil vol. 17 (2): pp. 349-366.

DíEZ-PiCAZO, Luis (1996): Fundamentos de Derecho Civil Patrimonial (Madrid, Editorial Civitas) 909 pp.

DiEZ-PICAZO, Luis et al. (2002): Los principios del derecho europeo de contratos (Madrid, Editorial Civitas) 529 pp.

Eberstein, Hans (1995): “Arts. 85-88”, en: Schlechtriem, Peter (edit.), Commentary on the UN Convention the International Sale of Goods [CISG] (Traducc. Thomas GeOfFrey, Oxford, Editorial Clarendon Press-Oxford).

ENDERlein, Fritz (1991): “Artículo 77”, en: Enderlein, Fritz et al. (edit.) Internationales Kaufrecht (Berlín, Editorial Haufe).

FENOY, Nieves (1996): Falta de conformidad e incumplimiento en la compraventa (Evolución del ordenamiento español) (Madrid, Editorial Reus) 611 pp.

FENOY, Nieves (2005): “Sentencia de 10 de julio de 2003”, Cuadernos civitas de jurisprudencia civil, vol. LXVIII: pp. 509-556.

FENOY, Nieves (2006): El sistema de protección del comprador (Madrid, Colegio Nacional de Registradores) 366 pp.

FERRARI, Franco (1995): "Uniform Law of International Sales: Issues of Applicability and Private International", Law Journal of Law and Commerce (15): pp. 159-174. 
FERRARINI, Guido (1981): "Il controllo dei rischi come criterio di responsabilità nella vendita internazionale. La Vendita Internazionale. La Convenzione di Vienna dell'11 Aprile 1980", Quaderni di Giurisprudenza Commerciale vol. 39.

FORTIER, Vicente (1996): "Le contrat du commerce international à l'aune du raisonnable", Journale Droit International (2): pp. 315-379.

Galgano, Francesco (1983): Diritto Privato (Milano, Editorial Cedam) 960 pp.

GARro, Alejandro (1990): "The Gap-Filling Role of the UNIDROIT Principles in International Sales Law: Some Comments on the Interplay between the Principles and the CISG", Tulane Law Review vol. 69: pp. 1149-1190.

Gimeno, Vicente (1986), Derecho procesal, en Almagro et al. (edit.), (Valencia, Editorial Tirant lo Blanch).

Goldschmidt, James (1936): Derecho Procesal Civil (Traducc. Leonardo Prieto, Buenos Aires, Editorial Labor).

Herber, Rolf (1995): "Article 6", en Schlechtriem, Peter (edit.), Commentary on the UN Convention the International Sale of Goods [CISG] (Traducc. Thomas GEOFFrEY, Oxford, Editorial Clarendon Press-Oxford).

HonNOLD, John, Uniform Law for International Sales (New York, 1991) pars. 454

Huber, Peter (1995a): "Arts. 49-51", en Schlechtriem, Peter (edit.), Commentary on the UN Convention the International Sale of Goods [CISG] (Traducc. Thomas Geoffrey, Oxford, Editorial Clarendon Press-Oxford) pp. 415-448.

Huber, Peter (1995b): "Art. 46", en Schlechtriem, Peter (edit.), Commentary on the UN Convention the International Sale of Goods [CISG] (Traducc. Thomas GEOFFREY, Oxford, Editorial Clarendon Press-Oxford) pp. 375-393.

INFANTE, Francisco (2002): "Apuntes sobre la Reforma alemana sobre el Derecho de las Obligaciones: la necesitada modernización del Derecho de las Obligaciones y la gran solución", Revista de Derecho Patrimonial vol. 8: pp. 152-175.

KAROLluS, Martin (1995): Judicial Interpretation and Application of the CISG in Germany 1988-1994. Disponible en: http://www.cisg.law.pace.edu/cisg/biblio/ karollus.html.

KNAPP, Victor (1987): “Art. 77, Mitigation of Damages”, en: BIANCA y BONELl (edit.), Commentary on the International Sales Law, The Vienna Sales Convention (Milan, Editorial Giuffré) pp. 538-567.

KRITZER, Albert (1994): Guide to practical applications of the United Nations Convention on International Sale of Goods (Boston, Kluwer Law and Taxation Publishers)

LANDO, Ole (2000): Principles of European Contract Law, Parts I and II (Boston, Kluwer Law International).

LAMARCA, Albert (2001): "La modernización del derecho alemán de las obligaciones: la reforma de BGB", en: Indret, (2): disponible en www.indret.com.

LOOKOFSKY, Joseph (1996a): Consequential Damages in Comparative Context (Copenhagen)

LOOKOFSKY, Joseph (1996b): Understanding the CISG in Scandinavian. A compact Guide to the 1980 United Nations Convention on Contracts for International Sale of Goods (Copenhagen, DJOF Publishing). 
LOOKOFSKY, Joseph (1993): The 1980 United Nations Convention on Contracts for the International Sale of Goods, en International Encyclopedia of Laws (Holanda, Kluwer Law and Taxation Publishers).

LOO, Martín (2005): Incumplimiento contractual en el ámbito de la compraventa internacional y el transporte marítimo (Santiago, Editorial LexisNexis) 187 pp.

LÓPEZ, Ángel (1998): “Artículo 48”, en: DíEZ-PiCAZO y PONCE DE LEÓn, Luis (edit.), La compraventa internacional de mercaderias. Comentario de la Convención de Viena (Madrid, Editorial Civitas) 427-434.

MARTíneZ, Anselmo (1999): "La prescripción de las acciones de la CISG derivadas de la falta de conformidad de las cosas entregadas", Rudolf Meyer zum Abschied: Dialog Deutschland-Schweiz VII (Genève, Ediciones Université de Genève) pp. 165-183.

MASKOW y ENDERLEIN (1992): International Sales Law. United Nations Convention on Contracts for the International Sale of Goods, Convention on the Limitation Period in the International Sale of Goods (New York, Editorial Oceana).

MessineO, Francesco (1952): Manuale di diritto civile e commerciale (Milano, Giuffrè Editore) $650 \mathrm{pp}$.

Montes, Vicente (1998): “Artículo 82”, en: Díez-PiCazo y POnCE de LeÓn, Luis (edit.), La compraventa internacional de mercaderías. Comentario de la Convención de Viena (Madrid, Editorial Civitas) pp. 671-679.

Morales, Manuel (1997): "Responsabilidad contractual en la Convención de Viena", Conferencia ofrecida en la Escuela de Derecho de la Pontificia Universidad Católica de Valparaiso [sin publicar] (Valparaíso).

Morales, Antonio Manuel (1998): “Artículos 35-36”, en: Díez-Picazo y PONCE DE LEÓN, Luis (edit.), La compraventa internacional de mercaderías. Comentario de la Convención de Viena (Madrid, Editorial Civitas) pp. 286-318.

Morales, Antonio Manuel (2003a): "Adaptación del Código Civil al Derecho Europeo de la compraventa", El Dret civil català en el context europeu. Materials de les Dotzenes Jornades de Dret Català a Tossa vol. XII: pp. 109-149.

Morales, Antonio Manuel (2003b): "Adaptación del Código Civil al Derecho Europeo: La compraventa" Anuario de Derecho Civil vol. 56 (4): pp. 1609-1652.

MORALES, Antonio Manuel et al. (2004): "La conformidad según la Directiva", Garantías en la venta de bienes de consumo / Les garanties dans la vente de biens de consommation (Santiago de Compostela, Publicaciones Universidad Santiago de Compostela) pp. 39-60.

MORALES, Antonio Manuel (2005): "El derecho a la reparación o sustitución de la cosa no conforme y la naturaleza de la obligación del vendedor", Mélanges offerts à JeanLuc Aubert: Propos sur les obligations et quelques autres thèmes fondamenteaux du droit (Paris, Editorial Dalloz) pp. 261-270.

NiCHOLAS, Barry (1997): "Fault and Breach of Contract", en: BEATSON y FriEDMAN (edit.), Good Faith and Fault in Contract Law (Oxford, Clarendon Press-Oxford) pp. 578.

Nicholas, Barry (1989): “The Vienna Convention on International Sales Law”, Law Quarterly Review vol. 105: pp. 201-243. 
NichOlas, Barry (1979): "Force Majeure and Frustration", American Journal of Comparative Law: pp. 231-241.

PAILlAS, Enrique (2006): La compraventa internacional de mercaderías (Santiago, Editorial Jurídica de Chile) 162 pp.

PANTAlEÓn, Fernando (1991): "El sistema de responsabilidad contractual (Materiales para un debate)", Anuario de Derecho Civil vol. 44 (3): pp. 1019-1091.

PANTALEÓn, Fernando (1993): "Las nuevas bases de la responsabilidad contractual", Anuario de Derecho Civil vol. 46 (4): pp. 1719-1745.

Pantaleón, Fernando (1998): “Artículo 74", en: DíeZ-Picazo y Ponce de León, Luis (edit.), La compraventa internacional de mercaderias. Comentario de la Convención de Viena (Madrid, Editorial Civitas) pp. 579-628.

Pietro-Castro, Leonardo (1982): Tratado de Derecho procesal civil. Proceso declarativo. Proceso de ejecución (Pamplona, Revista de Derecho Privado).

PILTZ, Burghard (1998): Compraventa internacional. Convención de Viena sobre compraventa internacional de mercaderías de 1980 (Traducc. Alfredo DE ASTREA y Ricardo DE Palma, Buenos Aires, Editorial Astrea) 194 pp.

Salvador, Pablo (1998): “Artículo 79”, en: Díez-PiCazo y Ponce de León, Luis (edit.), La compraventa internacional de mercaderías. Comentario de la Convención de Viena (Madrid, Editorial Civitas) pp. 635-660.

SAN Miguel, Lis Paula (2004): Resolución de contrato por incumplimiento y modalidades de su ejercicio (Madrid, Colegio de Registradores de la Propiedad y Mercantiles de España) 546 pp.

SCHLECHTRIEM, Peter (1986): "Uniform Sales Law. The UN-Convention on Contracts for the International Sale of Goods", Law Economics International Trade vol. 9: pp. 25 y ss.

Schlechtriem, Peter (1998): “Article 25”, en: Schlechtriem, Peter (edit.), Commentary on the UN Convention the International Sale of Goods [CISG] (Traducc. por Thomas GeOfFrey, Oxford, Clarendon Press-Oxford) pp. 173-185.

Soler, Ana (1998 a): "Artículo 77”, en: DíeZ-PiCAZO y PONCE DE LeÓn, Luis (edit.), La compraventa internacional de mercaderías. Comentario de la Convención de Viena (Madrid, Editorial Civitas) pp. 609-628.

Soler, Ana (1998 b): La Valoración del Daño en el Contrato de Compraventa (Pamplona, Aranzandi) $278 \mathrm{pp}$.

SCHWEnZER, Ingeborg (1998): “Article 35”, en: SCHLEChtriem, Peter (edit.), Commentary on the UN Convention the International Sale of Goods [CISG] (Traducc. por Thomas GeOffrey, Oxford, Clarendon Press-Oxford) pp. 274-289.

Stoll, Hans (1998): "Article 77", en: SChlechtriem, Peter (edit.), Commentary on the UN Convention the International Sale of Goods [CISG] (Traducc. por Thomas Geoffrey, Oxford, Clarendon Press-Oxford) pp. 585 y ss.

Tallon, Denis (1987): "Article 79, Exemptions", en: BianCa y Bonell (edit.), Commentary on the International Sales Law, The Vienna Sales Convention (Milan, Giuffrè), pp. 572-595.

Treitel, Guenter (1994): Frustration and Force Majeure (Londres, Sweet E Maxwell) 673 pp. 
Treitel, Guenter (1998): Remedies for Breach of Contract. A comparative account (Oxford, Clarendon Press-Oxford) 422 pp.

UlRICH, Magnus (1995): “General Principles of UN-Sales Law”, Rabels Zeitschrift vol. 59.

VÁSQUEZ, Tomás (2000): La compraventa internacional de mercaderías. Una visión jurisprudencial (Navarra, Editorial Aranzadi) 352 pp.

VIDAL, Álvaro (2003a): "Integración de la Convención de Viena sobre compraventa internacional de mercaderías", Revista de Derecho Universidad Católica de Valparaíso vol. 21: pp. 457-491.

VIDAL, Álvaro (2003b): "La función integradora de los principios generales del derecho en la compraventa internacional de mercaderías y en los Principios de la Unidroit sobre contratos comerciales internacionales", Anuario de Derecho Civil 56 (3): pp. 993-1040.

VIDAL, Álvaro (2003c): "La noción de persona razonable en la compraventa internacional”, en: Cabanillas SÁnchez, Antonio (edit.), Estudios Jurídicos en Homenaje al Profesor Luis Diez-Picazo y Ponce de León, II (Madrid, Editorial Civitas).

VIDAL, Álvaro (2005): "La gestión razonable de los efectos del incumplimiento en la compraventa internacional”, Revista de Derecho Universidad Austral vol. II: pp. 55-81.

VIDAL, Álvaro (2005a): "Incardinación de la responsabilidad por daños y el concepto de obligación en la compraventa internacional de mercaderías", Ius et Praxis vol. 11: pp. 303-330.

VIDAL, Álvaro (2005b): “Atribución y exoneración de responsabilidad en la compraventa internacional. Construcción de las reglas a partir de artículo 79 de la Convención de Viena”, en: Revista de Derecho Universidad Austral, vol. I: pp. 55-88.

VIDAL, Álvaro (2006): "La responsabilidad del deudor por incumplimiento de su tercero encargado en la compraventa internacional de mercaderías", Cuadernos de Actualidad Jurídica, pp. 259-295.

Will, Michael (1987): "Article 46", en: BiAnCA y BONELl (edit.), Commentary on the International Sales Law, The Vienna Sales Convention (Milan, Giuffrè) pp. 333-341.

WiTZ, Claude (1995): Les premières applications jurisprudentielles du droit uniforme de la vente internationale (Paris, Ediciones L.G.D.J.) 178 pp.

ZweIgerT y KÖTZ (1992) : An Introduction to Comparative Law (Traducc. Tony Weir, Oxford, Claredons Paperbacks) pp. 744.

\section{JURISPRUDENCIA CITADA}

Fauba France FDIS GC Electronique con Fujitsu Microelectronik GmbH (1992) : Cour d'Appel de Paris 22 abril 1992 [fecha de consulta : 24 octubre 2006]. Resumen en inglés disponible en: http://cisgw3.law.pace.edu/cases/920422f1.html; y texto original en: http://www.unilex.info/case.cfm?pid=1\&do=case \&id=142\&step=FullText

Partes no disponible (2001): Oberster Gerichtshof 22 octubre 2001 [fecha de consulta: 24 octubre 2006]. Texto original y resumen en inglés disponible en: http:// www.unilex.info/case.cfm?pid=1\&do=case \&id=764\&step=FullText 
American Biophysics v. Dubois Marine Specialties, alkla Dubois Motor Sports (2006): U. S. District Court, Rhode Island District el 30 enero 2006 [fecha de consulta : 24 octubre 2006]. Texto original y resumen en inglés: http://www.unilex.info/ case.. fm? pid $=1 \&$ do $=$ case $\&$ id $=1085 \&$ step $=$ FullText

Partes no disponible (2004): Tribunale d'Apello di Lugano 4 junio 2004 [fecha de consulta 24 octubre 2006]. Texto original y extracto en inglés disponible en Internet en: http://www.unilex.info/case.cfm?pid=1\&do=case $\&$ id=984\&step=FullText y su texto en inglés en: http://cisgw3.law.pace.edu/cases/031029s1.html

\section{NORMAS CITADAS}

Ley No 26, Norma General para la Defensa de los Consumidores y Usuarios (España), 19 julio 1984.

Ley No 23, Norma de garantías en la venta de bienes de consumo (España).

Ley No19.496, Norma sobre protección de los derechos de los consumidores. Diario Oficial 7 marzo 1997.

Convención de las Naciones Unidas sobre los Contratos de Compraventa Internacional de Mercaderías, suscrito en Viena, el 11 de abril de 1980. Diario Oficial, 3 octubre 1990. 
